\title{
Chemical Potential-Induced Wall State Transitions in Plant Cell Growth
}

\author{
Mariusz A. Pietruszka ${ }^{1}$ (D)
}

Received: 29 April 2019 / Accepted: 9 September 2019 / Published online: 23 September 2019

(c) The Author(s) 2019

\begin{abstract}
The $\mathrm{pH} / T$ duality of acidic $\mathrm{pH}$ and temperature $(T)$ action for the growth of grass shoots was examined in order to derive the phenomenological equation of wall properties for living plants. By considering non-meristematic growth as a dynamic series of state transitions (STs) in the extending primary wall, the critical exponents were identified, which exhibit a singular behaviour at a critical temperature, critical $\mathrm{pH}$ and critical chemical potential $(\mu)$ in the form of four power laws: $f_{\pi}(\tau) \propto|\tau|^{\beta-1}$, $f_{\tau}(\pi) \propto|\pi|^{1-\alpha}, g_{\mu}(\tau) \propto|\tau|^{-2-\alpha+2 \beta}$ and $g_{\tau}(\mu) \propto|\mu|^{2-\alpha}$. The indices $\alpha$ and $\beta$ are constants, while $\pi$ and $\tau$ represent a reduced $\mathrm{pH}$ and reduced temperature, respectively. The convexity relation $\alpha+\beta \geq 2$ for practical $\mathrm{pH}$-based analysis and $\beta \equiv 2$ "meanfield" value in microscopic $(\mu)$ representation were derived. In this scenario, the magnitude that is decisive is the chemical potential of the $\mathrm{H}^{+}$ions, which force subsequent STs and growth. Furthermore, observation that the growth rate is generally proportional to the product of the Euler beta functions of $T$ and $\mathrm{pH}$, allowed to determine the hidden content of the Lockhart constant $\Phi$. It turned out that the $\mathrm{pH}$-dependent time evolution equation explains either the monotonic growth or periodic extension that is usually observed-like the one detected in pollen tubes-in a unified account.
\end{abstract}

Keywords Assisted migration $\cdot$ Climate change $\cdot$ Critical exponent $\cdot$ Grass shoot $\cdot$ Maize $\cdot \mathrm{pH} \cdot$ Polar growth $\cdot$ Pollen tube . Polymer wall $\cdot$ Power law $\cdot$ Root hair $\cdot$ Scaling relation $\cdot$ Temperature

\begin{tabular}{ll}
\multicolumn{2}{l}{ Abbreviations } \\
APW & Artificial pond water \\
EWS & Equation of wall state \\
FC & Fusicoccin \\
IAA & Auxin (indole-3-acetic acid) \\
LOS & Loss of stability (model) \\
$\mu$ & Chemical potential \\
$\mu_{\mathrm{H}+}$ & Chemical potential of protons \\
$P$ & Turgor pressure \\
$P_{C}$ & Critical turgor \\
$\mathrm{pH}$ & Non-separable variable name; $\mathrm{pH}$ scaled $[0$, \\
& $14] \rightarrow[0,1]$ \\
$\mathrm{PM}$ & Plasma membrane \\
$\mathrm{SF}(\mathrm{s})$ & State function(s) \\
$\mathrm{SLs}$ & Strigolactones
\end{tabular}

Electronic supplementary material The online version of this article (https://doi.org/10.1007/s00344-019-10026-x) contains supplementary material, which is available to authorized users.

Mariusz A. Pietruszka

mariusz.pietruszka@us.edu.pl;

mariusz.a.pietruszka@gmail.com

1 Faculty of Biology and Environment Protection, University of Silesia, Katowice, Poland

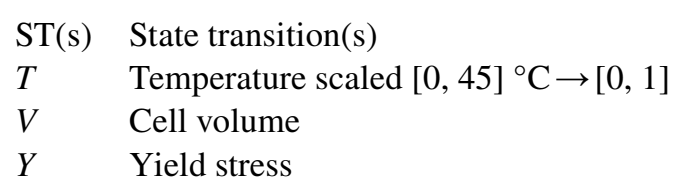

\section{Introduction}

The procedure for seeking explanations for the different modes of plant growth may include analytical models capable of describing the properties of a wall, cell time evolution, or both.

\section{Equation of Wall Properties for Plant Cells}

Hence, the derivation of an equation of wall state (EWS) for plants that integrate the relationship between temperature and $\mathrm{pH}$ (or chemical potential) with growth is one of the goals of this article. Based on reliable published datasets (Yan and Hunt 1999, Hager 2003) and auxiliary experimental data in the theoretical model, it was sought to identify the state variables that are necessary to describe optimal growth from the physical point of view, i.e. via $\mathrm{pH}$ or chemical potential, turgor pressure and temperature. The limited 
number of parameters can be misleading; this approach does not oversimplify the complexity of biological systems, but conversely takes all of them into account by building an outer scaffold that cannot be surpassed. One cannot dismiss the possibility that this is the role of phenomenology in making universal statements, in this case imposing a physical constraint (i.e. EWS) on the extending primary wall.

A commonly held view is that biological systems are complex (and molecular biologists are deluged with data), and that therefore modelling has to cope with the fact that the degrees of freedom are numerous, and correspondingly, the number of parameters should be high. The associations that exist between these parameters may in turn cause the emergent properties due to those relationships. Though physical systems on a microscopic scale are also complex and the number of degrees of freedom in real systems is abundant (e.g. Avogadro number, as in the solid-state physics), their behaviour can usually be described by a few parameters (e.g. Ginzburg 2004) within the framework of a phenomenological theory. A similar argument also concerns advanced quantum model(s) (e.g. Hubbard 1963), which has only two parameters: $t$ - for the hopping integral and $U$-for the Coulomb interaction of electrons within narrow energy bands. In what follows, it is argued that, similar to physical systems, a low number of relevant parameters can also be sufficient to describe complex biological systems. To support this view, let me quote Portes et al. (2015): "This is not to invalidate the strive for detailed models, which are necessary to understand the role of specific components of interest, however, they require a compatible amount of data. In contrast, more general models help to unveil the fundamental principles driving a phenomenon of interest, helping to identify the key regulatory interactions, albeit lacking details". In what follows, the second route was chosen.

The growth of plant cells and organs (like extending cylindrical organs such as pollen tubes, root hairs or grass shoots) are affected by light and humidity, which along with $\mathrm{pH}$ and temperature are the most important factors that influence growth. It can be a rewarding enterprise to understand plant growth in terms of the time evolution of STs (e.g. from an ordered to a disordered state, from a stressed to a relaxed state, from a "covalent bonds state" to a "disruption of covalent bonds state", etc.) that take place in the peripheral cell wall. Changes in pH (Ortega et al. 2015; Rayle and Cleland 1992) have been shown to relax the wall stresses presumably by disrupting the load-bearing bonds. Such a transition ('state transition', ST, or equivalently 'state change', which should not be confused with the phase transition that is encountered in physics, since the system is not at an equilibrium steady state) occurs via the exchange of particles and energy-consuming metabolic processes, such as energyconserving ATP, with the inside of cell compartment- the vacuole and cytoplasm, which are treated as the reservoirs of molecules and heat (thermostat). Hence, living organisms were considered to be open systems that dissipate energy and exchange entropy (heat) and matter (molecules) with the environment (Barbacci et al. 2015), a thermostat. This process is accomplished by the presence of $\mathrm{pH}$ - and $T$-dependent Euler beta functions in model equations, which represent the modes of interaction (like heat and mass transfer) with the outside world of a growing plant. Even though I considered a single ST, a cascade (ratchet) of subsequent chemical potential-induced dynamic STs, which may constitute the extension of the cell wall and growth, can be imagined. The prevailing role of the chemical potential was demonstrated and it was proposed that the growth of plant cells and organs is regulated, at the molecular level, by the chemical potential (Matlak et al. 2004; van der Marel 2004) of $\mathrm{H}^{+}$ions. I also show, at a phenomenological level, that the ionic fluxes may generate power-law relations. The proposed model correctly accounted for the set of experimental results and predicted the growth of grass shoots from $\mathrm{pH}$ with a high fidelity. To my knowledge, this research is the first attempt to use a statistical physics methods in calculation of critical exponents to model the cell wall during expansive growth and I believe it can provide critical insights on cell wall dynamics at a molecular level (this behaviour could be for a specific type of plant).

Plant developmental systems have evolved within the universal limitations that are imposed by the plant cell wall (Lintilhac 2014). Modulation of the mechanical properties occurs through the control of the biochemical composition and the degree and nature of interlinking between cell wall polysaccharides (Bidhendi and Geitmann 2016). Plant cells encase themselves in a complex polysaccharide wall (Cosgrove 2005a) and characteristically obtain most of their energy from sunlight via the photosynthesis of the primary chloroplasts. The expansive growth of turgid cells, which is defined as an irreversible increase in cell volume, can be regarded as a physical process that is governed by the mechanical properties of the cell wall and the osmotic properties of the protoplast (Schopfer 2006). The precise biochemical mechanism that regulates the ability of the growth-limiting walls to extend irreversibly under the force of turgor pressure has not yet been identified (Kutschera 2000), but it is correlated with the loosening of cells walls, which increases the cell's susceptibility to expansion.

Growing plant cells characteristically exhibit acid growth (Rayle and Cleland 1970; Hager et al. 1971; Cosgrove 1989), which has been formulated in the form of the "acid growth hypothesis" originally independently proposed by Cleland and Hager (Cleland 1971; Hager et al. 1971; Taiz and Zeiger 2006). The acid growth hypothesis was proposed almost 50 years ago and is widely considered to play a role in expansive cell growth. The acid growth hypothesis postulates that both phytotoxin fusicoccin $(\mathrm{FC})$ and the 
growth-promoting factor auxin (indole-3-acetic acid, IAA) cause wall loosening and produce the concomitant induction of growth (growth enhancement) through the rapid acidification of the extension-limiting cell wall (Cleland 1973; Kutschera 1994). These enigmatic "wall-loosening processes" are, in fact, minor changes within the polymer network of the extension-limiting walls, i.e. the incorporation of proteins, the enzymatic splitting of polymer backbones or covalent cross-links or the disruption of non-covalent interactions between wall polymers via expansin activity (McQueen-Mason and Cosgrove 1994; Dyson et al. 2012). Molecular studies revealed that expansins are a large family of proteins with 38 members in Arabidopsis thaliana, which can be divided into three subfamilies: $\alpha-, \beta$ - and $\gamma$-expansins ( $\mathrm{Li}$ et al. 2002). It was shown that individual expansins might be tissue- or process-specific, and that a loss-of-function mutation resulted in a disorder in a specific aspect of plant growth or development, for example, in root hair development (reviewed by Marzec et al. 2015a).

Growth is accomplished through the enlargement of the cell volume owing to water uptake, which maintains the appropriate inside pressure in the vacuole as well as the irreversible extension of the pre-existing (primary) cell wall. Hereafter, an almost constant or slowly varying turgor pressure is assumed, which by definition is a force that is generated by water pushing outward on the plasma membrane and plant cell wall that results in rigidity in a plant cell and the plant as a whole.

Expansive growth is the result of the coupling effects (Barbacci et al. 2013) between mechanical (pressure), thermal (temperature) and chemical energy $(\mathrm{pH})$. The thermal sensitivity of biochemical processes refers to the coupling effect between the thermal and chemical energies. In the search for a plant-specific EWS in growing biological cells or non-meristematic tissues, I considered two state variables, namely 'physiological' temperature $T$ (from 0 to 45 degrees in the Celsius scale) and $\mathrm{pH}$ at a constant turgor. Note that $\mathrm{pH}$ is not sensu stricto a fundamental physical quantity, and therefore, cannot be treated as a usual intensive variable. Nonetheless, relying on the definition of $\mathrm{pH}$ and then considering the chemical potential (Baierlein 2001), the following model is proposed.

Evidence has accumulated that the final goal of auxin action (Steinacher et al. 2012; Lüthen 2015; Majda and Robert 2018) is to activate the plasma membrane (PM) $\mathrm{H}^{+}$-ATPase, a process that excretes $\mathrm{H}^{+}$ions into the cell wall. The auxin-enhanced $\mathrm{H}^{+}$-pumping lowers the cell wall $\mathrm{pH}$, activates $\mathrm{pH}$-sensitive enzymes and proteins such as expansins (Cosgrove 1993), xyloglucans (Fry et al. 1992) or yieldings (Okamoto-Nakazato et al. 2001) within the wall and initiates cell wall loosening and extension growth. It has also been observed that when auxin-depleted segments were submerged in an acid buffer solution, the segments started their elongation growth immediately ("acid growth"), whereas the auxin-induced growth ("auxin growth") began after a delay (lag phase), as is shown in Fig. 1 (curve 1) in Hager (2003); see also the remaining plots, which are of quite a different character, (curves 2-6) that correspond to "acid growth". From the many investigations that have been done for more than four decades, it has been deduced that protons, which are exerted into the wall compartment, are directly responsible for the wall-loosening processes through the hydrolysis of covalent bonds, transglycosylation or the disruption of non-covalent bonds (thus changing the state of the system). The growth effect is illustrated in Fig. 2 in Hager (2003), where the "Zuwachs" (increments in \%) is plotted against $\mathrm{pH}$.

However, $\mathrm{pH}$ can be expressed in terms of a more elementary quantity, namely the chemical potential $\mu_{\mathrm{H}+}$. Note that indirect measurements of the chemical potential by means of $\mathrm{pH}$ can be compared to previous measurements of the electromotive force (EMF) in order to detect phase transitions, which are localised by the kinks in the chemical potential in condensed matter physics (Matlak and Pietruszka 2000; Matlak et al. 2001). Although $\mathrm{pH}$ is not a typical generalised coordinate, the microscopic state of the system can be expressed through it in a collective way.

Temperature is among the most important environmental factors that determine plant growth and cell wall yielding. Plants are responsive to temperature and some species can distinguish differences of $1{ }^{\circ} \mathrm{C}$. In Arabidopsis, a warmer temperature accelerates flowering and increases elongation growth (Jung et al. 2016). In many cases, the process of

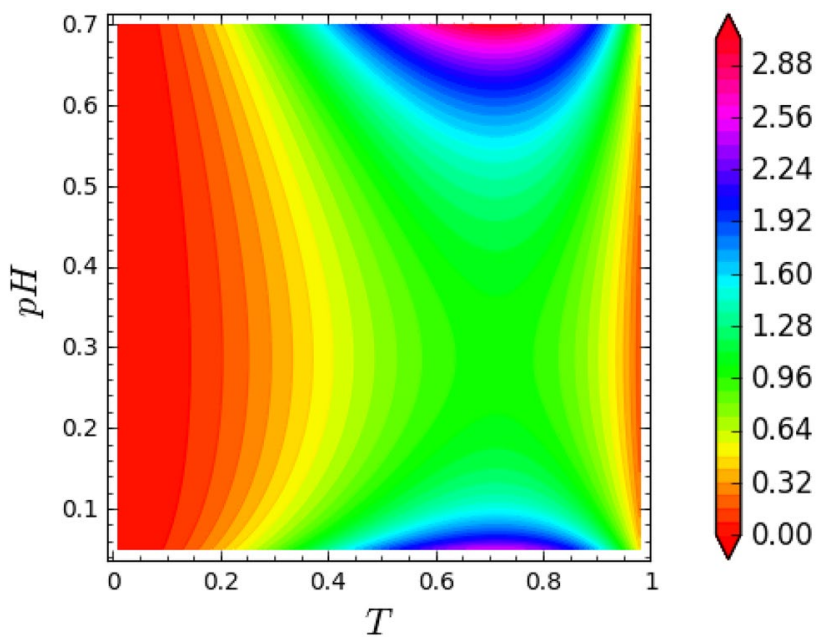

Fig. 1 Plot of the function $f$ given by Eq. (3) showing the optimum conditions for plant cell/organ growth. Both coordinates, temperature $(T)$ and acidity or basicity (alkaline medium) $\mathrm{pH}$, are rescaled to unity. The best conditions for maximum growth (green) are found at the saddle point (a stationary point). The simulation parameters that were used are similar to those that were used for auxin-induced growth—see SI Table 1 (Color figure online) 

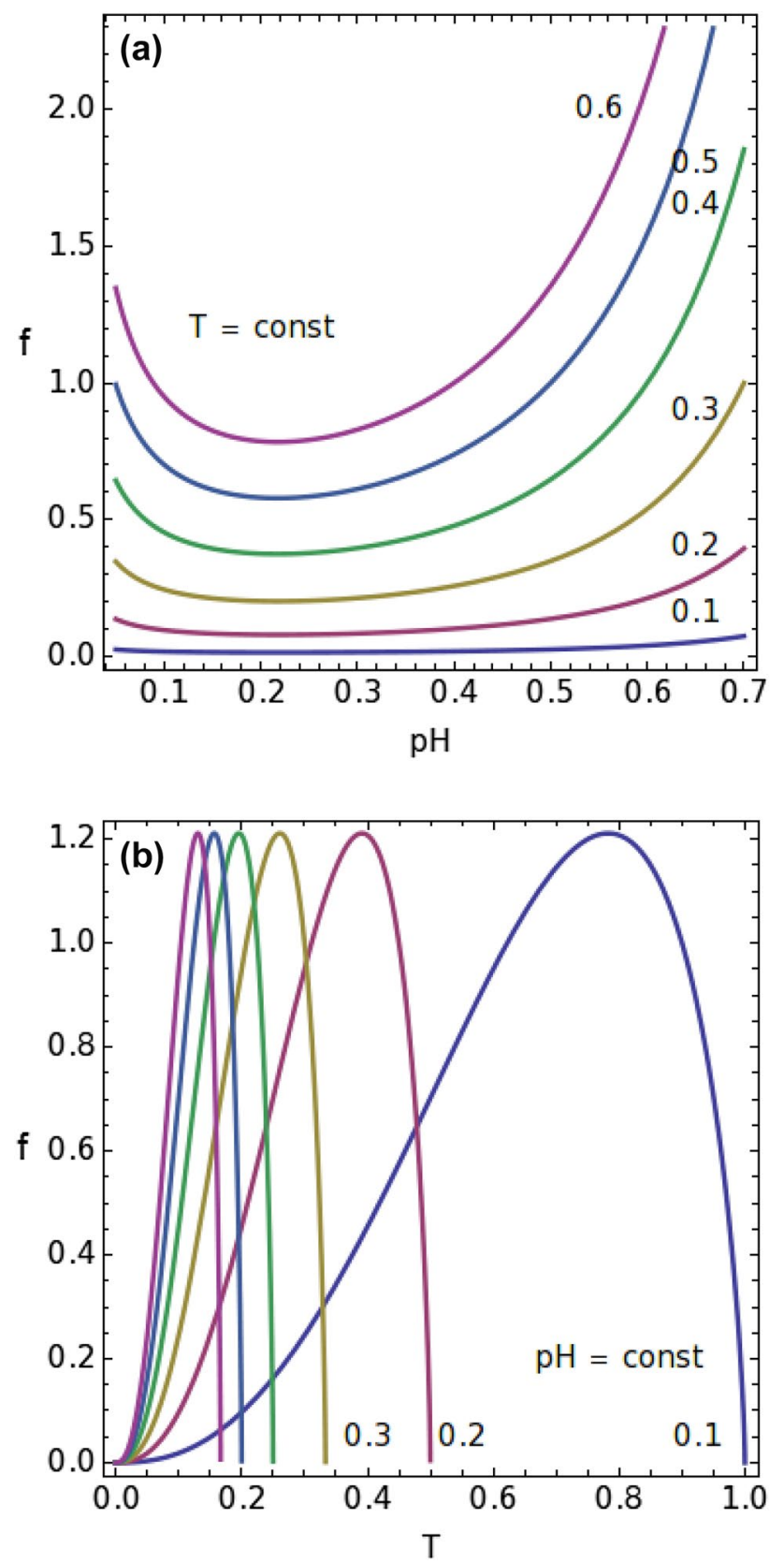

Fig. 2 The a isotherms (scaled values indicated) as a function of $\mathrm{pH}$ (scaled) of the function $f$, Eq. (3); $\mathbf{b}$ constant $\mathrm{pH}$ curves as a function of temperature (scaled). Simulation parameters: $\alpha=1.7$ and $\beta=3.52$ (SI Table 1)

growth can be differentiated by the response of plants to temperature (Went 1953). Actually, only a few papers in which the temperature response is treated as a major problem can be mentioned (Yan and Hunt 1999 and papers cited therein), but some recent publications have highlighted the role of temperature as a factor that regulates plant development, i.e. via phytohormones (Dockter et al. 2014; Jung et al. 2016).
Inspired by the Ansatz using Euler beta function $f(x, \alpha$, $\beta$ ) for growth empirical data, I will show that the final outcome of temperature and $\mathrm{pH}$ on plant growth is effectively similar, even though both of the triggers of these responses are apparently of a different nature.

\section{Time Evolution Equation of Plant Cells}

Next, the question was posed of whether the cell volume extension or elongation growth of plants (represented by expanding volume $V$ ) can be adequately predicted by $\mathrm{pH}$, temperature and pressure.

Modulation of the mechanical properties during expansive growth is still a 'hot topic' for the plant cell growth community, e.g. recently in Sridhar et al. (2018), Bidhendi and Geitmann (2016), Boudon et al. (2015), Barbacci et al. (2013) and Rojas et al. (2011), to name a few. Plant cell expansion, in turn, is controlled by the balance between the intracellular turgor pressure, cell wall synthesis and stress relaxation. Several mainstream explanations of the mechanical aspects of cell growth have been considered in publications, beginning with the cell wall model (Holdaway-Clarke and Hepler 2003) through the instability model (Wei and Lintilhac 2007) and the hydrodynamic model (Zonia and Munnik, 2007) to the statistical model of cell wall dynamics during expansive growth (Sridhar et al. 2018). I propose that these apparently conflicting visions of cell wall extension and growth may be consolidated in a unifying chemical potential-based explanation, which converges in a coherent picture of this somewhat elusive topic.

The last few years have witnessed significant progress in uncovering the molecular basis that underlies plant cell elongation and expansion. In many cases, the first step in cell growth is related to a restriction of the symplasmic communication between neighbouring cells, which permits a specialisation programme that is specific for the individual cell to begin (Marzec and Kurczynska 2014). This isolation enables cells from multicellular organisms to be considered to be individual cells. Afterwards, different signalling and developmental mechanisms are run in order to induce either the expansion of the entire cell or localised elongation. The roles of different protein classes have been described based on the analysis of the growth of pollen or root hair tubes, which are the models that are used in investigations of tip growth (Higashiyama and Takeuchi 2015; Marzec et al. 2015a). Among them, the function of expansins, the proteins that are involved in plant cell wall loosening, which is related to cell wall acidification, has been confirmed in both monocot and dicot species. Analysis of different mutants in the genes encoding expansins confirmed their role based on the analysis of plant phenotypes (Cosgrove 2015). Nevertheless, a mathematical model that permits the cell status 
of mutant and wild-type plants to be compared might prove useful for further investigations.

According to the acid growth hypothesis, auxin plays a pivotal role in the growth of plant cells (Hager 2003; Lüthen 2015; Majda and Robert 2018 for review). However, recent reports have indicated that a new class of plant hormones, strigolactones (SLs), cooperate with auxin in many developmental processes such as shoot and root branching under normal and stress conditions (Marzec et al. 2013b). Additionally, new functions of SLs, which indicate that those hormones may play a key role in the regulation of plant growth and development, have been proposed (Marzec and Muszyńska 2015). Until now, most data have indicated that SLs influence auxin transport via the distribution of PIN proteins (Shinohara et al. 2013; Pietruszka and Lewicka 2007), but it has also been proposed that SLs influence secondary growth in plants (Agusti et al. 2011) and cell elongation (Hu et al. 2010; Koltai et al. 2010). Mathematical formulas that permit cell growth under different treatments to be measured and described may shed new light on the hormonal regulation of plant cell elongation.

From the physical point of view, the basic ingredients of an expanding plant cell are the cell wall, plasma membrane and cytoplasm. Together, they form a system that can be described as a two-compartment structure with the plasma membrane being treated as the interface between the cytoplasm and the wall. On the other hand, the intensive quantities can be attributed to the system of volume $V$, namely pressure, and the chemical potential, the latter of which is directly related to a measurable quantity- $\mathrm{pH}$. The problem of the volumetric growth of plant cells, which lies at the intersection of physics, biochemistry and composite materials of a nanometric scale, is inherently difficult to capture in a single theoretical frame (Breidwood et al. 2014). Therefore, the goal was to deconstruct all of the above-mentioned approaches in order to assemble a model that is based on physical principles that are also able to admit other perspectives. It is believed that the EWS that was proposed above has the ability to do this, although its relevance to many of the growth details may be beyond the scope of this conjecture.

\section{Chemical Wall-Loosening Approach}

It is believed that the cell wall has active mechanisms for self regulation (Hepler and Winship 2010). The cell wall is formed through the activity of the cytoplasm and maintains a close relationship with it. Communication occurs between the cell wall and the cytoplasm and the plasma membrane occupies a pivotal position in transmitting particles and information. In this model, when applied to pollen tube growth, cell growth is ultimately dependent on the biochemical modification of the wall at the apical part where exocytosis is believed to occur (Holdaway-Clarke and Hepler 2003). Cell wall loosening then allows turgorinduced stretching, thereby pulling the flow of water into the cell (down its potential gradient). During oscillatory growth, enzymes that interfere with wall loosening are believed to be periodically activated or inhibited, which is supposed to drive oscillations in growth and the growth rate (as commented by Zonia 2010). In this approach, the passive role of turgor pressure is stressed.

\section{Loss of Stability Model}

A new look at the physics of cell wall behaviour during plant cell growth, which focuses on the purely mechanical aspects of extension growth such as wall stresses, strains and cell geometry, was investigated within the framework of a model that was based on the Eulerian concept of instability (Wei and Lintilhac 2003, 2007). It was demonstrated that loss of stability (LOS) and consequent growth are the inevitable result of the increasing internal pressure in a cylindrical cell (such as the internodal cylindrical cells of intact Chara corallina plants) once a critical level of pressure-induced stress $\left(P_{c}\right)$ is reached. This model apparently challenged the viscoelastic or creep-based models (Ray et al. 1972; Cosgrove 1993; Schopfer 2006), which were designated as chemical wall loosening and was questioned by Schopfer (2008), who asserted that stress relaxation can be attributed to chemorheological changes in the load-bearing polymer network that permit the plastic deformation of wall dimensions. In his words, the "growth of turgid cells is initiated and maintained by chemical modifications of the cell wall (wall loosening) followed by mechanical stress relaxation generating a driving force for osmotic water uptake". In response to Schopfer's letter, Wei and Lintilhac (2008) claimed that LOS did not challenge the principles of osmotic water relations or biochemically mediated wall loosening and emphasised that plant cells are both osmometers and pressure vessels, and therefore, both facts should be accommodated in any meaningful model. However, the problem of the water potential difference $\Delta \Psi=\Psi_{\mathrm{o}}-\Psi_{\mathrm{i}}$ of a growing cell and a "mysterious pump" if pressures must rise to drive LOS behaviour still remained. Regardless of whether the new wall synthesis is homogeneous or patchy (the cell wall can always be conceptually shrunk to a patch), it will affect cell behaviour by modifying the turgor pressure in short time scale oscillations $\delta P$ (Pietruszka and Haduch-Sendecka 2015a), which are specifically enhanced by the flow of the osmotic pressure through the entire cell volume (beyond the apex as well).

\section{Hydrodynamic Model}

Recent works have revealed an important role for osmotic pressure and the hydraulic features of the system in driving 
cell shape restructuring and growth (Proseus et al. 2000; Proseus and Boyer 2006; Zonia et al. 2006, 2010; HaduchSendecka et al. 2014). This concept was established by works that revealed an important role for hydrodynamics in pollen tube growth. The main message that hydrodynamics have the potential to integrate and synchronise the function of the broader signalling network (in pollen tubes) was expressed by Zonia (2010). Pascal's principle states that pressure exerted anywhere in a confined incompressible fluid (cell sap) is transmitted in all directions equally throughout the fluid in such a way that the pressure variations (initial differences) remain the same. Indeed, according to Pascal's principle, turgor pressure is a fast (propagation equal to the velocity of sound in the fluid-soap-medium) and isotropic messenger in the time-evolving cell. Moreover, hypotonic or hypertonic treatment of the periodically elongating cells of pollen tubes led to the recognition that the growth rate oscillation frequency was "doubled" or "halved" with respect to the unperturbed (isotonic) mode (Zonia 2010). The oscillation frequency in such a system has been determined (Pietruszka 2013) to obey the following relation: $\omega \sim \sqrt{ } P$, which means that the oscillation growth angular frequency is directly related to the pressure.

From these brief accounts, the question arises-What drives plant cell growth-cell wall loosening or osmotic pressure? Even though there is consent about the role of cell wall properties and turgor pressure in growth, a discrepancy about what drives the initial episode of cell extension exists (Zonia and Munnik 2007). One model proposes that cell wall loosening occurs first and permits the expansion of the cell due to decreased wall rigidity. There is considerable evidence to support this view (Cosgrove 2005b). However, cytomechanical studies have revealed that the viscoelastic properties of the pollen tube cell wall in the apical growth zone do not change considerably (Geitmann and Parre 2004) during growth oscillations. Hence, it was suggested that the cycles of cell wall loosening cannot be the driving force of oscillatory growth (Zonia and Munnik 2007). Moreover, it was shown that increased pressure induces the expansion of the cell wall and drives growth in Chara cells (Proseus et al. 2000; Proseus and Boyer 2006). An intermediate LOS model was put forward (Wei and Lintilhac 2003; Wei et al. 2006) that proposed a gradual increase of turgor pressure to a critical point at which the loss of stability initiates wall extension and growth.

\section{Statistical Model}

Global biophysical models such as those of Lockhart and Ortega have provided crucial macroscopic understanding of the expansive growth process, but they lack the connection to molecular processes that trigger network rearrangements in the wall. Sridhar et al. (2018) attempted to fill in this gap by introducing the statistics of tethers connected to microfibrils constituting the mechanical scaffold of the extending primary wall. The tethers are governed by the Poisson point process that has the property that each point is stochastically independent to all the other points in the process. The main advantage of this approach is a consistency with the previous findings (expressed by the Ortega equation), while the disadvantage is the lack of temperature, decisive for the development of plants. The expansive growth, as presented by the authors is a passive process, forced by pressure. Nonetheless, the presence of viscoplastic and viscoelastic terms mapped onto a statistics of independently acting elastic springs (tethers) is very appealing. The detachment and reattachment events causing irreversible deformation of the expanding cell wall seem very convincing in the first order of approximation (independent events, tethers acting as a parallel assembly of springs). The tether properties are described by molecular scale parameters and, in principle, can be obtained from experiments. Interestingly, the calculated relaxation half-time $t_{1 / 2}$ is identical to the one obtained in Pietruszka (2011).

The statistical model can be compared with the concept of STs taking place in the extending primary wall. The latter, expressed in terms of this work, can occur at subsequent time slices, where the tethers statistically detach causing cell expansion. Indeed, the authors state that "wall length arise due to discrete events of tether detachment". If the statistics of this events was big enough causing a ST, a step in length increase can arise leading to pollen tube oscillations.

Without going further into the details of the ongoing discussion (e.g. Zonia and Munnik 2007; Winship et al. 2010, 2011; Sridhar et al. 2018) and bringing together these different opinions, I propose a chemical potential based scenario. In what follows, I have intentionally omitted irrelevant details in order to make the main steps clear when introducing it and to build a story with a logical flow.

\section{Materials and Methods}

\section{Plant Material}

In order to check the equations, limited experiments were performed using 3-day-old seedlings of Zea mays L cv. Cosmo (Nasiona Kobierzyc. Sp. z o.o. Hodowla roślin rolniczych-Kobierzyce, Poland; courtesy of my PhD student Monika Olszewska). The maize seeds were soaked in tap water for $2 \mathrm{~h}$, and then sown in moist lignin. The seedlings were grown in an incubator in darkness at $27 \pm 0.5^{\circ} \mathrm{C}$ for 3 days, because this temperature has been defined to grow maize the fastest. Ten $\mathrm{mm}$ segments were cut from the plants $5 \mathrm{~mm}$ below the tip and first leaf was removed. 


\section{Simultaneous Measurement of Growth and Acidification}

The growth of intact seedlings of maize (Zea mays L.) and $\mathrm{pH}$ of the incubation medium was simultaneously investigated. The growth rates were measured by applying a non-invasive technique that records time-lapse images of the macroscopic elongation of the coleoptiles, while changes in the $\mathrm{pH}$ were monitored using a pH/Ion meter (see Olszewska et al. 2018, Supplementary Information, Fig. S1 for the experimental design). The experiment was performed for artificial pond water (APW: $0.1 \mathrm{mM} \mathrm{NaCl}, 0.1 \mathrm{mM} \mathrm{CaCl}_{2}, 1 \mathrm{mM} \mathrm{KCl} ; \mathrm{pH}$ 6.5 established by $\mathrm{HCl}$ or $\mathrm{NaOH}$ ) conditions. Thirty ten-mmlong coleoptile segments were prepared and then placed in two identical sets (stacks of 15 coleoptiles) of the elongationmeasuring apparatus in an aerated incubation medium (ibid.). The volume of the incubation medium in the apparatus was $5 \mathrm{ml}$ per glass tube $(0.3 \mathrm{ml}$ of the incubation medium per segment). Measurements of the growth and $\mathrm{pH}$ were performed for $12.5 \mathrm{~h}$ and recorded every $15 \mathrm{~min}$. The $\mathrm{pH}$ measurement was carried out using two CPI-501 pH-meters. The accuracy level was $0.002 \mathrm{pH}$, according to the manufacturer's information. Images of the segments were recorded using a CCD camera (Hama Webcam AC-150). Only one of the two probes in separate tubes was selected for analysis. The total length of coleoptiles in one column was $15 \times$ (the length of a single coleoptile), corresponding to the number of repetitions equal to 15 times. The total length of the 15 coleoptile segments (each initially ten-mm-long) was measured in the ImageJ program (ImageJ program bundled with 64-bit Java 1.8.0) with the accuracy established at the $\pm 0.1 \mathrm{~mm}$ level. The relative elongation was calculated using the formula $\left(l_{t}-l_{0}\right) / l_{0}$ with $l$ for "length" and $l_{0}=l\left(t=t_{0}\right)=10 \mathrm{~mm}$. Also, it was assumed that the coleoptile segment is a cylinder and therefore the crosssection area is a circle. Under an optical microscope (Motic Microscope RED233 at a $\times 20$ magnification), the radius $r$ of the circle for coleoptile cross-section was measured to be equal $0.344 \pm 0.001 \mathrm{~mm}$. Then, using the formula $\pi r^{2}$, the surface of a circle was calculated to be $0.372 \mathrm{~mm}^{2}$. Then, the relative volume was obtained by multiplying the length of the coleoptile segment by the average $(n=15)$ cross-section area. The temperature during this auxiliary experiment was $25 \pm 0.5^{\circ} \mathrm{C}$ and was maintained using a water bath at a similar level. All manipulations were performed under dim green light.

\section{Results}

\section{Equation of Wall Properties for Plant Cells}

Based on the "acid growth hypothesis" and relevant experimental data (Yan and Hunt 1999; Hager 2003; Pietruszka et al. 2007), the $\mathrm{pH} / T$ (or $\mu / T$ ) duality of acidic $\mathrm{pH}$ or auxin-induced acidification and temperature for the growth of grass shoots was examined in order to determine the model equation (EWS) for the extending primary wall of living plants. In order to introduce $\mathrm{pH}$ and $T$ scaling, let us start from basic definitions and data.

\section{Construction of a Phenomenological Model}

In the literature, $\mathrm{pH}$ is defined as the decimal logarithm of the reciprocal of the hydrogen ion activity $\mathrm{a}_{\mathrm{H}+}$ in a solution $\mathrm{pH}=-\log _{10} \mathrm{a}_{\mathrm{H}+}=\log _{10} 1 / \mathrm{a}_{\mathrm{H}+}$ (Covington et al. 1985). The $\mathrm{pH}$ value is a logarithmic measure of $\mathrm{H}^{+}$-activity (the tendency of a solution to take $\mathrm{H}^{+}$) in aqueous solutions and defines their acidity or alkalinity; $\mathrm{a}_{\mathrm{H}+}$ denotes the activity of hydronium ions in units of mol/l. The logarithmic $\mathrm{pH}$ scale ranges from 0 to 14 .

The temperatures at which most physiological processes normally occur in plants range from approximately $0{ }^{\circ} \mathrm{C}$ to $45^{\circ} \mathrm{C}$, which determines the physiological temperature scale (in Kelvin scale: $[\mathrm{K}]=\left[{ }^{\circ} \mathrm{C}\right]+273.15$ ). The temperature responses of plants include all of the biological processes throughout the biochemical reactions (high $\mathrm{Q}_{10}$ factor). This is clearly visible in the relative rates of all of the development or growth processes of maize as a function of temperature, which is illustrated in Fig. 3 in Yan and Hunt (1999) and ranges from 0 to $45^{\circ} \mathrm{C}$. Therefore, to be "on the safe side", I propose that the 'physiological' temperature scale for plants $[0-45]^{\circ} \mathrm{C}$, which corresponds to a $[0,1]$ interval after rescaling, be setup. Otherwise, diverse temperature scales can be introduced in different situations.

Which data have been adopted for the research and how those data have been handled are described below. For the analysis, I accepted the reliable published data, namely the pH plots that are presented in Hager (2003) and the temperature plots that are presented in Yan and Hunt (1999). These charts were first digitised by a GetData Graph Digitizer (version 2.26.0.20) for reconstruction and then rescaled (see SI Fig. 1). The original temperature range $[0,45]{ }^{\circ} \mathrm{C}$ was converted to a $[0,1]$ interval by dividing by 45 . The same procedure was conducted on the $\mathrm{pH}$ scale $[0,14]$ in order to obtain the normalised $[0,1]$ interval (SI Fig. 1), which was indispensable for the further calculations. Very low or very high $\mathrm{pH}$ values are obviously not physiological at least for higher plants, however, such excessive conditions, which constitute unacceptable extremes for life to come to existence, are excluded by nature. Nonetheless, the $[0,14] \mathrm{pH}$ scale should be mapped as a whole to a 0 to 1 range to establish the normalised scale, free form any arbitrary assignment.

The $\mathrm{pH}$ plots that are presented in Fig. 2 in Hager (2003) as well as the temperature plots that are presented in Fig. 3 in Yan and Hunt (1999) look similar when mirror symmetry is applied. Providing that a substitution $x \rightarrow(1-x)$ 

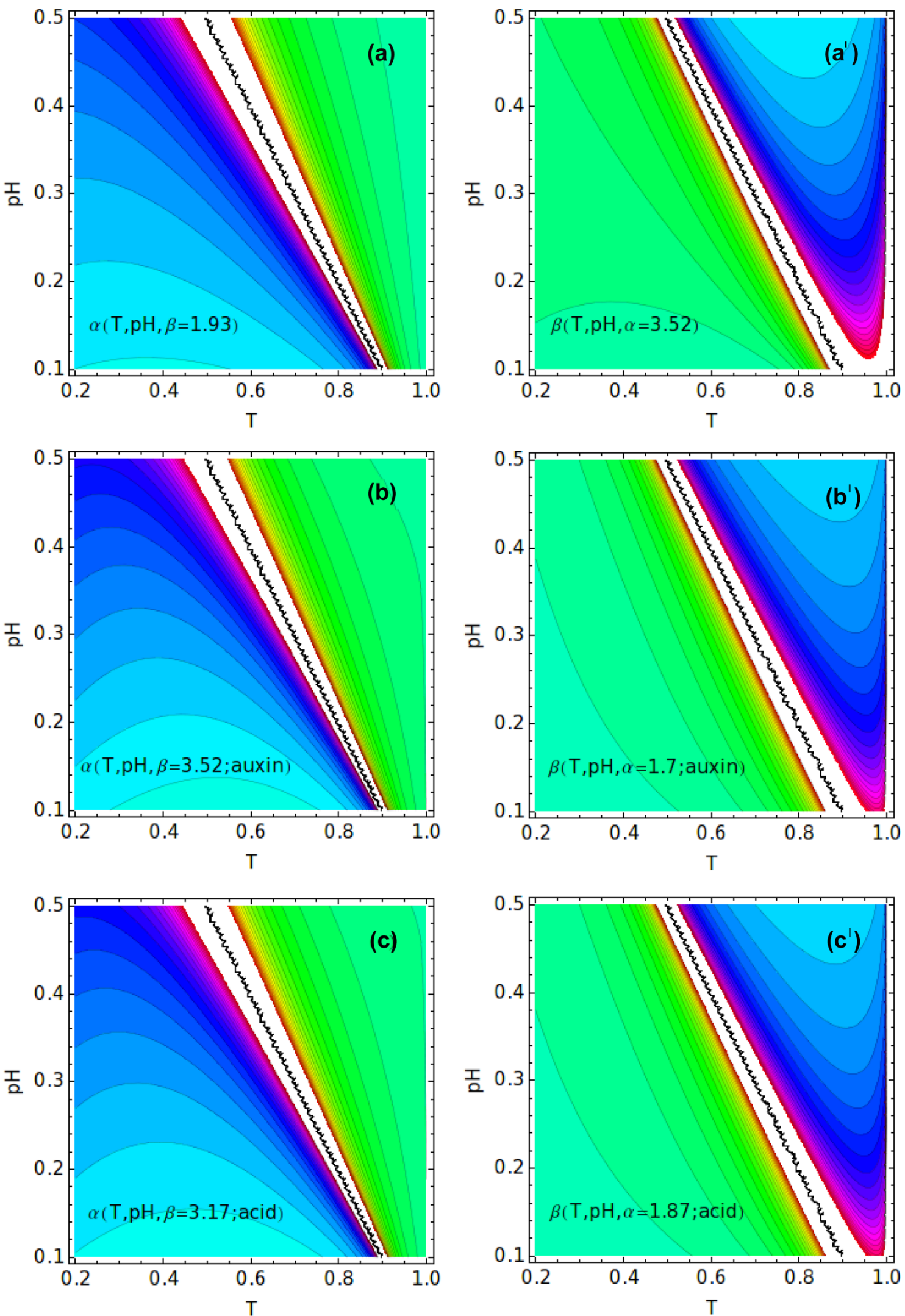

Fig. 3 Solutions (state diagrams) for $\alpha$ and $\beta$ exponents in the $T$ and $\mathrm{pH}$ coordinates (both rescaled). The lines of the $(\mathbf{a}, \mathbf{b}, \mathbf{c})$ constant $\alpha$ and the $\left(\mathbf{a}^{\prime}, \mathbf{b}^{\prime}, \mathbf{c}^{\prime}\right) \beta$-values in $(T, \mathrm{pH})$ coordinates are indicated in the

charts. Simulation data are presented in the figure legends. Greennegative values, blue-positive (Color figure online) 
is performed and a function $f(x)$ of variable $x$ and of its reflection $(1-x)$ is considered, one might expect that they will look approximately the same after the correct scaling. These properties can be adequately described by the Euler beta density distribution (or beta Euler, for short). In this approach, let us assume that $x$ equals either $\mathrm{pH}$ or temperature (both rescaled to a $[0,1]$ interval), an assignment which makes sense since at a relatively low $\mathrm{pH}$, which corresponds to a relatively high temperature in this unit-scaling, plant cells and organs grow (elongate) the fastest, which is clearly reproduced in SI Fig. 1.

The data from SI Fig. 1a were taken separately ("auxin" and "acid" growth; Hager, 2003) for the fitting procedure (SI Table 1 and SI Fig. 2), while the temperature data (Yan and Hunt 1999) from SI Fig. 1b were first normalised and then fitted by beta Euler. Furthermore, when comparing the data from different experiments (Yan and Hunt 1999; Hager 2003), it is observed that the $x$ variable could, after rescaling, have the following meaning — either acidity (basicity) $x \equiv \mathrm{pH}$ or temperature $x \equiv T$ (see SI Fig. 1) with a characteristic beta function cut-off at $x=0$ (SI Fig. 1a and the inset) and at $x=1$ (SI Fig. 1b); the normalised scale that was used is presented in SI Fig. 1b (inset).

\section{Derivation of the EWS for Plants}

The probability density function of the beta distribution also called the Euler integral of the first kind (Polyanin and Chernoutsan 2011) for $0 \leq x \leq 1$ and shape parameters $\alpha$ and $\beta>0$ is a power function of the variable $x$

$$
\begin{aligned}
f(x ; \alpha, \beta) & =\text { const } \cdot x^{\alpha-1}(1-x)^{\beta-1} \\
& =\frac{x^{\alpha-1}(1-x)^{\beta-1}}{\int_{0}^{1} u^{\alpha-1}(1-u)^{\beta-1} \mathrm{~d} u}=\frac{1}{B(\alpha, \beta)} x^{\alpha-1}(1-x)^{\beta-1}
\end{aligned}
$$

where $B=B(\alpha, \beta)$ is the normalisation constant. Based on the experimental observations as discussed in the previous section and presented in SI Fig. 1, the left side of Eq. (1), rewritten twice, first for $x=\mathrm{pH}$, then $x=T$, can be merged into a single expression

$\left[c_{\mathrm{pH}} \cdot \mathrm{pH}^{\alpha_{1}-1}(1-\mathrm{pH})^{\beta_{1}-1}\right]_{T, \text { reflected }} \approx\left[c_{T} \cdot T^{\beta_{2}-1}(1-T)^{\alpha_{2}-1}\right]_{\mathrm{pH}}$

with a condition that $T$ and $\mathrm{pH}$ are normalised and dimensionless; $\mathrm{c}_{\mathrm{pH}}$ and $\mathrm{c}_{\mathrm{T}}$ are constants normalising the maxima of the beta functions to 1 , and " $\mathrm{pH}$ " is hereafter treated as a non-separable variable name. The lower indices " $T$ " and "pH" in Eq. (2) should be read "at constant temperature" and "at constant $\mathrm{pH}$ ", respectively, which is valid for the preparation of strict experimental conditions to achieve a stable equilibrium (Lüthen et al. 1990; Hager 2003). The appropriate (i.e. symmetric with respect to $x=0.5$ line) values of $T$ and $\mathrm{pH}$ should be taken into account in Eq. 2). The equality sign and the equalisation $\alpha_{1}=\alpha_{2} \equiv \alpha, \beta_{1}=\beta_{2} \equiv \beta$ as well as $c_{T}=c_{\mathrm{pH}}$ in Eq. (2) seem to be justified for biological systems (see SI Fig. 1.1) in the first order of approximation. Such a modified Eq. (2) will be considered further as a constraint on the two independent variables $T$ and $\mathrm{pH}$.

By defining a new function $f$ at constant turgor pressure $P$ (isobaric conditions: $\delta P \approx 0$ ) according to

$\left.f(T, \mathrm{pH} ; \alpha, \beta)\right|_{P} \equiv\left(\frac{T}{1-\mathrm{pH}}\right)^{\beta-1}\left(\frac{1-T}{\mathrm{pH}}\right)^{\alpha-1}$

that is an analytic function of $\mathrm{pH}$ and $T$ on the physically accessible interval $[0,1)$ for each variable (here function $f$ constructs a bridge between the physical and chemical features of the living system), and assuming adequate water uptake to fulfil this requirement, we determine from Eq. (2)

$\frac{T^{\beta-1}(1-T)^{\alpha-1}}{p H^{\alpha-1}(1-\mathrm{pH})^{\beta-1}}=1$

After rearrangement, the constitutive dimensionless EWS for living plant cells reads

$\left(\frac{T}{1-\mathrm{pH}}\right)^{\beta-1}\left(\frac{1-T}{\mathrm{pH}}\right)^{\alpha-1}=1$

which has the elegant structure of a double power law. $T$ in Eq. 5 is the temperature in Celsius rescaled to a $[0,1]$ interval as $\mathrm{pH}$ also is. Here, the constants $\alpha$ and $\beta$ are the shape exponents (SI Table 1 and SI Fig. 2). The saddle-point type of Eq. (3) that is presented in Fig. 1 represents a concave surface in the form of a contour plot, which is roughly accurate at low $\mathrm{pH}$ and moderate temperatures. Equation (5) becomes increasingly inaccurate (divergent) at very low or very high $\mathrm{pH}$ values (close to zero or one in the normalised scale, which is used throughout of the article), though such extreme conditions are not admitted by nature and can be ignored. The isotherms of Eq. (3) are presented in Fig. 2a, while the lines of constant $\mathrm{pH}$ are presented in Fig. $2 b$.

Even though the derivation was apparently launched from the "acid growth theory", a closer look at the model assumptions revealed that, in fact, it was based on the typical raw experimental data of $\mathrm{pH}$ - and $T$-dependent growth (SI Fig. 1). For that reason, Eq. (5) is independent of whether the acid growth theory applies or not, and therefore, seems universal, at least for tip-growing grass shoots. Note, Eq. (5) is not an evolution (growth) equation, but a system (cell wall) property equation. The solutions of Eq. (5) for $\alpha$ and $\beta$ in the form of contour plots are presented in Fig. 3.

The essential relations are property relations and for that reason they are independent of the type of process. In other words, they are valid for any substance (here: the 
primary wall of a given plant species) that goes through any process or mode of extension. Yet, in the present case, we should be aware of the empirical origin of Eq. (5) and remember the fact that a fundamental variable of the system is the chemical potential $\mu$ at a constant pressure and temperature (here: $\mu=\mu_{\mathrm{H}+}(T)$ for $\mathrm{H}^{+}$ions). By taking the total derivative, where the implicit $\mu_{\mathrm{H}+}(T)$ dependence is taken into account, we get

$d f(T, \mathrm{pH} ; \alpha, \beta) \approx d g(T, \mathrm{pH}(T) ; \alpha, \beta)=d g\left(T, \mu_{\mathrm{H}^{+}}(T) ; \alpha, \beta\right)$

where

\section{Calculating Critical Exponents}

Analytical evaluation must lead to predictions that can be used as a Litmus test in order to cut through the myriad of conceptual models that have been published in the biophysical community. In plant science, given that the calculation of critical exponents can be connected with the optimum growth, it can be helpful to identify the molecular mechanism that is responsible for growth (in principle, similar exponents should be connected with the same mechanism). It could also be a viable method when growth is stimulated

$\left.g\left(T, \mu_{\mathrm{H}^{+}}(T) ; \alpha, \beta\right)\right|_{P} \equiv-\frac{(\log 10)^{a}}{T-1}\left(\mu_{0}-\mu_{\mathrm{H}^{+}}\right)^{2}\left[\frac{T-1}{\left(\mu_{0}-\mu_{\mathrm{H}^{+}}\right) R T}\right]^{\alpha}\left[\frac{R T^{2}}{R T+\left(\mu_{0}-\mu_{\mathrm{H}^{+}}\right) \log 10}\right]^{\beta-1}$

In approximation, since $\mathrm{pH}$ is usually measured in isothermal conditions (SI Fig. 1a), let us temporarily suspend the $\mathrm{pH}(T)$ dependence in Eq. (6a). Equations (3) and (6) describe the mathematical relations between $\mathrm{pH}, T$ and $\mu_{\mathrm{H}+}$ variables.

Equation (5) is the EWS that describes the plant cell wall properties, where the SFs are the scaled temperature and $\mathrm{pH}$ of the expanding cell volume. Here, $\mathrm{pH}$, which is intimately connected with the acid growth hypothesis, introduces a direct link between the physical variables that represent the state of the system (growing cell or tissue) and the biological response (via $\mathrm{pH}$ altering $-\mathrm{H}^{+}-$ ATPase), which results in growth. Clearly, Eq. (5) can be further verified by the diverse experiments that have been conducted for many species in order to determine the characteristic triads $\left(\alpha, \beta, \Omega_{\mathrm{S}}\right)$ that belong to different species or families (classes) taxonomically, or that are simply controlled by growth factors (growth stimulators such as auxin, fusicoccin or inhibitors such as $\mathrm{CdCl}_{2}$ ). However, the real test of the utility of Eq. (5) would include the predictive outputs for any perturbations that could then be subject to experimental validation. From the dyads $(\alpha, \beta)$, Eq. (5) should also be able to connect with either the underlying physiological processes or with their molecular drivers. In particular, whether the underlying molecular mechanism is identical or different should be reflected in the critical exponents ( $\alpha$ and $\beta$ pair should be identical for the same molecular mechanism and dissimilar for diverse mechanism). Despite the fact that $f$ is not a generalised homogeneous function, it can also be used to check for a kind of "universality hypothesis" (Stanley 1971) and to validate the evolutionary paradigm with genuine numbers. (laser, UV, electromagnetic field, etc.). In physics, phase transitions occur in the thermodynamic limit at a certain temperature, which is called the critical temperature, $T_{\mathrm{c}}$, where the entire system is correlated (the radius of coherence $\xi$ becomes infinite at $T=T_{\mathrm{c}}$ ). Here, I want to describe the behaviour of the function $f(\mathrm{pH}, T)$, which is expressed in terms of a double power law by Eq. (3) that is close to the critical (optimum) temperature and, specifically in the considered case for practical reasons, also about the critical (optimum) $\mathrm{pH}=\mathrm{pH}_{\mathrm{c}}$. Critical exponents describe the behaviour of physical quantities near continuous phase transitions. It is believed, though not proven, that they are universal, i.e. they do not depend on the details of the system. Per analogia, since growth (such as cell wall extension in pollen tubes or the elongation growth of the shoots of grasses, coleoptiles or hypocotyls) can be imagined as advancing over the course of time, a series of non-equilibrium STs (see "Discussion"), the critical exponents can be calculated.

Lets introduce the dimensionless control parameter $(\tau)$ for a reduced temperature

$\tau=1-\frac{T}{T_{c}}$

and similarly $(\pi)$, for a reduced $\mathrm{pH}$

$\pi=1-\frac{\mathrm{pH}}{\mathrm{pH}_{c}}$

which are both zero at the transition, and calculate the critical exponents. It is important to keep in mind that (in physics) critical exponents represent the asymptotic behaviour at a phase transition, thus offering unique information about how the system (here: the polymer built cell wall) approaches a critical point. A critical point is defined as a point at which $\xi=\infty$ so in this sense $T=T_{\mathrm{c}}$ and $\mathrm{pH}=\mathrm{pH}_{\mathrm{c}}$ are critical points of Eq. (5). This property can help to determine 
the peculiar microscopic mechanism(s) that allows for wall extension (mode of extension) and growth in future research. The information that is gained from this asymptotic behaviour may advance our present knowledge of these processes and their mechanisms and help to establish the prevailing one.

By substituting Eqs. (7) and (8) into (3), one can calculate the critical exponents (when $T \rightarrow T_{c}$ and $\mathrm{pH} \rightarrow \mathrm{pH}_{c}$ ) from the definition (Stanley 1971), which will give us

$\lambda_{1}=\lim _{\tau \rightarrow 0} \frac{\log f(\tau, \pi)}{\log (\tau)}=\beta-1$

$\lambda_{2}=\lim _{\pi \rightarrow 0} \frac{\log f(\tau, \pi)}{\log (\pi)}=1-\alpha$

and

$\lambda_{3}=\lim _{\tau \rightarrow 0} \lim _{\pi \rightarrow 0} \frac{\log f(\tau, \pi)}{\log (\tau) \log (\pi)}=0$

here $\lambda_{1}=\beta-1$ and $\lambda_{2}=1-\alpha$ are the critical exponents $\left(\lambda_{3}=0\right)$. The above equations result in two power relations that are valid in the immediate vicinity of the critical points

$f_{\pi}(\tau) \propto|\tau|^{\beta-1}$

$f_{\tau}(\pi) \propto|\pi|^{1-\alpha}$

where lower indices denote constant magnitudes. Equations (12) and (13) represent the asymptotic behaviour of the function $f(\tau)$ as $\tau \rightarrow 0$ or $f(\pi)$ as $\pi \rightarrow 0$. In fact, we can observe a singular (divergent) behaviour at $T=T_{c}$ (Fig. 4a) and $\mathrm{pH}=\mathrm{pH}_{c}$ (Fig. $4 \mathrm{~b}$ ). At this bi-critical point, the following relation holds: $\alpha+\beta=2$. Thus, the exponents are related through scaling relations, in analogy with the static critical phenomena.

Retaining $\tau$ for a reduced temperature, let us introduce another-microscopic — control parameter, $\mu$, for the chemical potential

$\mu=1-\frac{\mu_{\mathrm{H}^{+}}}{\mu_{c}}$

Substituting $\tau$ and Eq. (14) into Eq. (6b) for $g(\mathrm{~T}, \mu)$ and assuming the reference potential $\mu_{0}=0$, one can calculate the critical exponents (when $T \rightarrow T_{c}$ and $\mu_{\mathrm{H}^{+}} \rightarrow \mu_{c}$ ) to get

$\lambda_{1}=\lim _{\tau \rightarrow 0} \frac{\log g(\tau, \mu)}{\log (\tau)}=-2-\alpha+2 \beta$
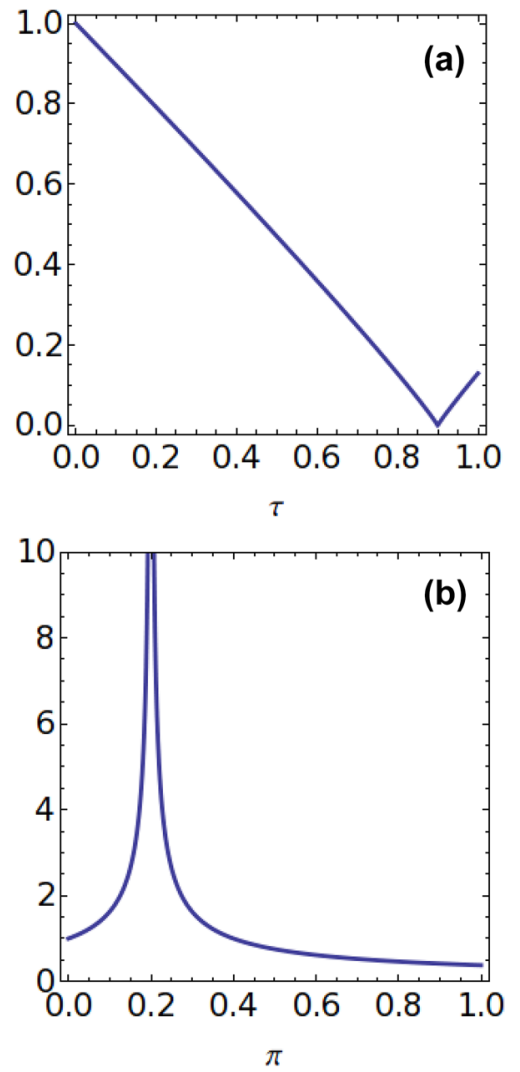

Fig. 4 Critical behaviour at the STs that take place in the cell wall (pH, $T$-variables). a A "kink" (discontinuity in the first derivative) at the critical temperature $T=T_{\mathrm{c}}$. b a "log-divergent" (" $\lambda$ "- - type) solution at the critical $\mathrm{pH}=\mathrm{pH}_{\mathrm{c}}$. Control parameters: reduced temperature $(\tau)$ and reduced $\mathrm{pH}(\pi)$. Simulation parameters: $\mathbf{a} \beta=1.93$ and b $\alpha=1.7$ (SI Table 1). This could be representative of distinct wallloosening mechanisms

$\lambda_{2}=\lim _{\mu \rightarrow 0} \frac{\log g(\tau, \mu)}{\log (\mu)}=2-\alpha$

$\lambda_{3}=\lim _{\tau \rightarrow 0} \lim _{\pi \rightarrow 0} \frac{\log g(\tau, \mu)}{\log (\tau) \log (\pi)}=0$

The above limits result in two more power relations, which are valid in the immediate vicinity of the critical points

$g_{\mu}(\tau) \propto|\tau|^{-2-\alpha+2 \beta}$

$g_{\tau}(\mu) \propto|\mu|^{2-\alpha}$

Equations (18) and (19) represent the asymptotic behaviour of the function $g(\tau, \mu)$ as $\tau \rightarrow 0$ or $g(\tau, \mu)$ as $\mu \rightarrow 0$. At the 

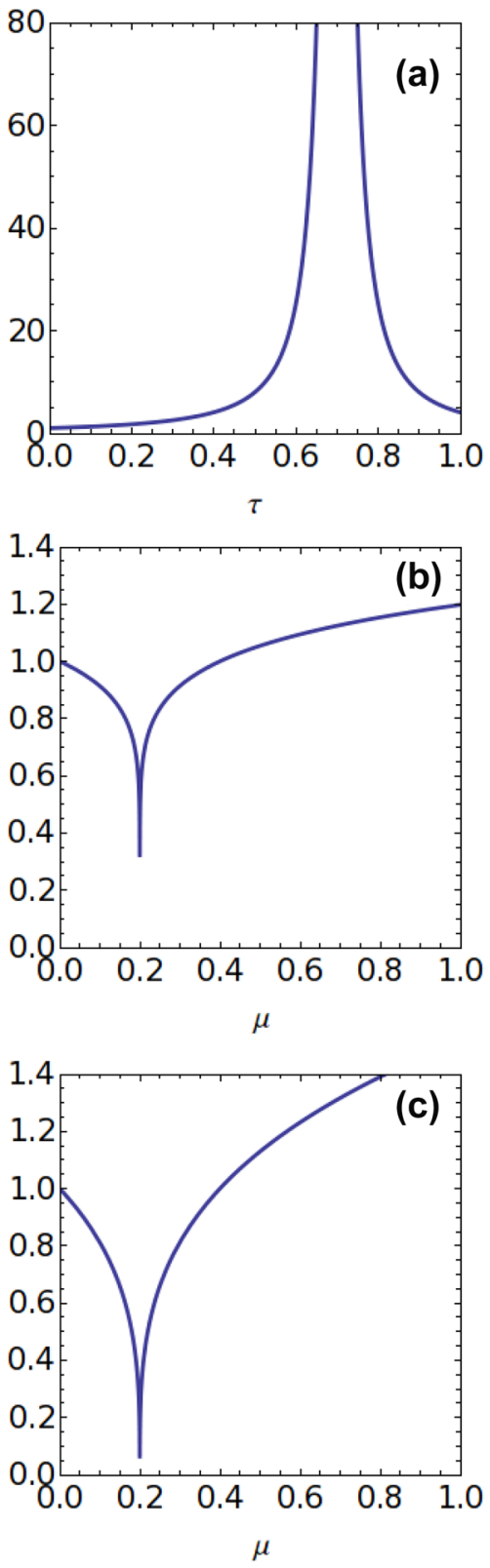

Fig. 5 Critical behaviour at the STs that take place in the cell wall (for $\mu, T$-variables). a A "log-divergent" (" $\lambda$ "-type) solution at $T=T_{\text {c }}$. b-c Solution at the critical value of the chemical potential $\mu=\mu_{\mathrm{c}} ; \mathbf{b}$ "acid growth", c "auxin growth" (SI Table 1). Control parameters: reduced temperature $(\tau)$ and chemical potential $(\mu)$. Simulation parameters: a $\alpha=3.52, \beta=1.93 ; \mathbf{b} \alpha=1.87, \beta=3.17$; $\mathbf{c} \alpha=1.7$ and $\beta=3.52$ (SI Table 1) microscopic level, we observe a singular behaviour at $T=T_{c}$ (Fig. 5a) and $\mu=\mu_{\mathrm{c}}$ (Fig. 5b, c).

For the bi-critical point, the exact relation $\beta=2$ holds (compare with SI Table 1 and SI Fig. 2), thus leaving us with the only free parameter $(\alpha)$ of the model. Note the broad peak at the critical temperature (indicating that optimal growth occurs within a certain temperature range) and a sharp, more pointed peak for the critical chemical potential. In this representation, growth can be treated as a series of subsequent STs that take place in the cell wall. It looks as though a cardinal quantity that is decisive for growth in this particular approach is the chemical potential.

Complex systems such as the cell wall of a growing plant are solid and liquid-like at the same time. At the molecular level, they are both ordered and disordered (allowing for the transition between these states). There are obviously complex interactions between the model parameters and inputs from many other kinds of inputs. However, the EWS describes the properties of the wall and unknown complex interactions in a general way. Whether the wall structure is ordered or disordered, universal features can be identified using simple scaling laws.

\section{Time Evolution Equation of Plant Cells}

If one imagines that the growth rate, as a function of $\mathrm{pH}$, has a (Euler) beta function form for any fixed temperature $(T)$ and a similar dependence as a function of $T$ for a fixed pH (see SI Table 1 and SI Fig. 1 and SI Fig. 1.1), one can conclude that the volumetric growth rate is proportional to the product of the beta functions of $T$ and $\mathrm{pH}$ (and to the effective turgor pressure $P-P_{c}$ ). This assertion can be the starting point for the heuristic derivation, in the first approximation in which one can neglect the nested $\mathrm{pH}\left(\mu_{\mathrm{H}+}(T)\right)$ dependence, of the equation below.

\section{Mystery of the Lockhart Coefficient Explained?}

Simply speaking, the above statement for the relative growth rate can be expressed in a way that is analogous to the Lockhart (1965) equation as an Ansatz ("educated guess") and can be postulated in the general form

$$
\underbrace{\frac{1}{V(t)} \frac{\mathrm{d} V(t)}{\mathrm{d} t}}_{\text {Relative growth rate }}=\underbrace{c \times \underbrace{T^{\alpha-1}(1-T)^{\beta-1}}_{f(T)} \times \underbrace{\mathrm{pH}^{\beta-1}(1-\mathrm{pH})^{\alpha-1}}_{\text {Turgor }} \times \Phi_{0}}_{\text {Lockhart constant }} \times \underbrace{\left(P-P_{c}\right)}
$$


at a constant turgor pressure $P$ and yield threshold $P_{c}$ (both in $[\mathrm{MPa}])$. Here, $\mathrm{c}$ is a scaling constant that is proportional to the reciprocate of the product of the beta function normalisation constants, see Eq. (1) and can be incorporated to $\Phi_{0}$ that was introduced for dimensionality reasons: $\left[\Phi_{0}\right]=\mathrm{MPa}^{-1} \times \mathrm{s}^{-1}$, as in the Lockhart equation. In Eq. (20) I assume concomitant water uptake; note that the $P-P_{c}$ term can be substituted with a more appropriate turgor plus osmotic pressure term in order to allow for water transport (via aquaporins) due to the changes in the osmotic and water potential (Obermayer, 2017 in Pollen Tip Growth)). $V=V(t)$ is the increasing volume of a growing cell over the course of time. Here, "pH" is treated, as before, as a non-separable variable name. In isothermal conditions, the integration of Eq. (20) yields the solution for the enlarging volume in the form analytic function of $\mathrm{pH}$ and $T$ on the physically accessible interval from 0 to 1 for each variable. However, the augmented form of the Lockhart equation, which is expressed by Eq. (20), provides the possibility to not only describe monotonic cell expansion correctly (Figs. 6, 7), but also the oscillatory mode of the extension of the pollen tubes. Apparently, especially in the case of oscillatory or just changing turgor pressure, the additional (viscoelastic) term $1 / \varepsilon \times \mathrm{d} P /$ $\mathrm{d} t$ can be introduced (added) into Eq. (20) on the right side, to become the Ortega-like equation (Ortega, 1985), for completeness. However, another proposal may include a variability of $P$ in agreement with $\mathrm{pH}$ changes (see the inset in Fig. 9) in a self-consistent solution of Eq. (20). This, in turn, can lead to the growth rate oscillations that are observed in pollen tubes. Additionally, the remarks concerning the possible changeability of $P_{c}(=Y$, a yield threshold) during

$V(t)=V(0) \times \exp \left[c \times T^{\alpha-1}(1-T)^{\beta-1} \times \Phi_{0} \times\left(P-P_{c}\right) \times \int_{0}^{t}\left[\mathrm{pH}(\tau)^{\beta-1}(1-\mathrm{pH}(\tau))^{\alpha-1}\right]_{T} \mathrm{~d} \tau\right]$

where 0 and $t$ denote the initial and final time. Note that, unlike the Lockhart equation, the 'acidification' that is present in Eq. (21), which is represented by the value of dynamic $\mathrm{pH}$, prevents a plant cell from unlimited exponential growth (burst). In contrary, the solution of the Lockhart equation $V(t)=V(0) \exp \left(\Phi_{0}\left(P-P_{c}\right)\right) t$ means that plants grow with no limitation, which is an apparent contradiction to real-life phenomena. Equation (21) correctly delivers not only the initial phase of slow, and next of rapid growth, but also the deceleration and saturation phases (Fig. 6). Equation (21) holds for dynamic pH-in Fig. 7 changes in the volume and saturation effect depend on the simulation parameters. The model suggests that the yielding behaviour encapsulated in the classical Lockhart equation can be explained by the strongly non-linear dependence of $V$ on $\mathrm{pH}$ and $T$.

By recalling the canonical form of the Lockhart equation with the extensibility $\Phi$ controlling the rate of growth

$\frac{1}{V(t)} \frac{\mathrm{d} V(t)}{\mathrm{d} t}=\Phi\left(P-P_{c}\right)$

and comparing Eqs. (20) and (22), one obtains the pHdependent estimate for the Lockhart constant:

$\Phi=\Phi(\mathrm{pH}, T)=c \times T^{\alpha-1}(1-T)^{\beta-1} \mathrm{pH}^{\beta-1}(1-\mathrm{pH})^{\alpha-1} \Phi_{0}$

where the exponents $\alpha$ and $\beta$ are numbers that are independent of $\mathrm{pH}$ (or $\mu$ ) and $T$, whereas $\mathrm{pH}=\mathrm{pH}(t)$. Note that Eq. (20) turns into its canonical-Lockhart form, Eq. (23), for $\alpha=\beta=1$ and $c=1$. Hence, the Lockhart coefficient $\Phi$, which is responsible for viscoplastic extensibility, is an
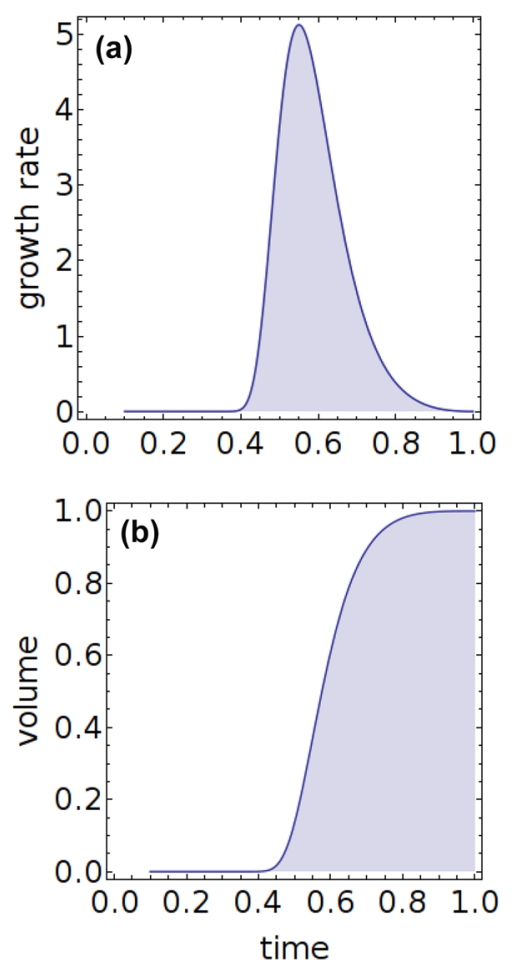

Fig. 6 a Growth rate plot obtained for Eq. (20) where pH was assumed to be inversely proportional to time (Lüthen et al. 1990, Fig. 6). Simulation data: $\alpha=3, \beta=2$; arbitrary units. b Typical growth curve obtained from Eq. (21) —all growth phases are clearly visible: initial phase of slow growth, accelerated growth, quasi-linear phase, deceleration and saturation (Fogg, 1975). See also Fig. 7 for parameterisation of Eq. (21) with respect to $\mathrm{pH}(7 \mathrm{a})$, temperature (7b) and turgor pressure $(7 \mathrm{c})$ 

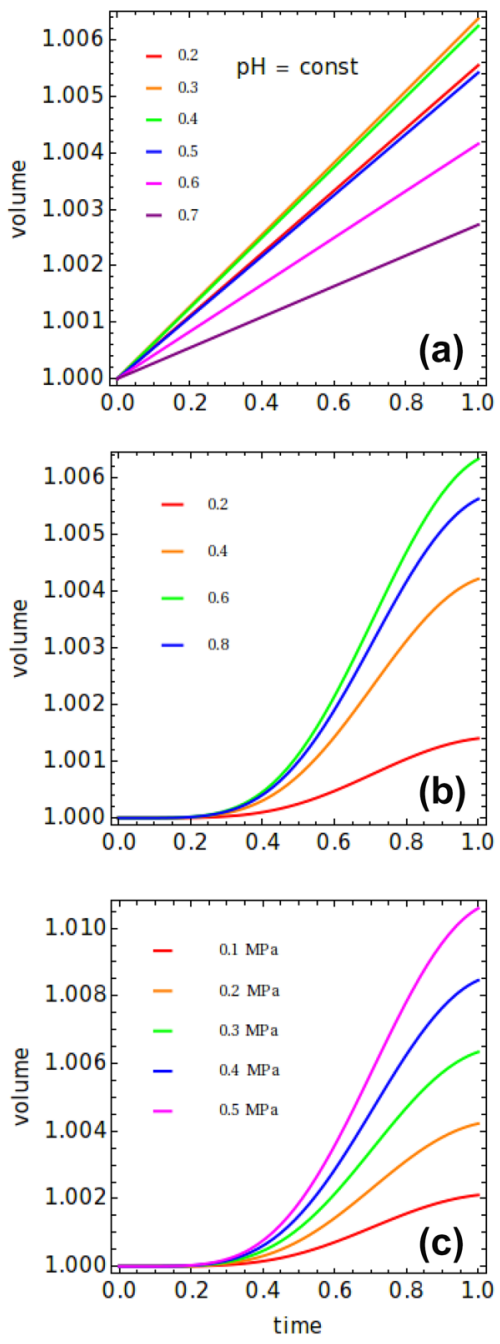

Fig. 7 Volumetric growth calculated from Eq. (21), an exemplary fit. a At constant pH. $P-P_{c}=0.3 \mathrm{MPa}, T=0.6\left(\sim 25^{\circ} \mathrm{C}\right)$; pH-scaled values $(0.2-0.7$, increment 0.1$)$ are shown in the plot ( $T$ and $\mathrm{pH}$ scaled to $[0,1]$ interval for all charts-see text). Note the linear character of the solution of Eq. (21) for $\mathrm{pH}=$ const and the maximum expansion for the normalised value of $\mathrm{pH} \sim 0.3-0.4$ (note that the slope of the volumetric extension does not increase sequentially with decreasing $\mathrm{pH}$ ). (b) For changing temperature $T$. Simulation parameters: $P$ $-P_{c}=0.3 \mathrm{MPa}, T=0.2,0.4,0.6,0.8$ (legend); $\mathrm{pH}$ decreases like $\sim 1 / t$. Note the typical sigmoid-like curve solution of Eq. $(21)$ over a $[0,1]$ time interval that corresponds to a rapid $(\sim 1 / t) \mathrm{pH}$ drop. Maximum extension (rate) is observed approximately for $T=0.6\left(\sim 25^{\circ} \mathrm{C}\right)$ and decreases at both higher and lower temperatures as is expected. $\mathbf{c}$ For changing effective turgor pressure $P-P_{c}$. Simulation parameters: $P$ $-P_{c}=0.1,0.2,0.3,0.4,0.5 \mathrm{MPa}$ (legend); $T=0.6\left(\sim 25^{\circ} \mathrm{C}\right)$. Note the sigmoid-like growth curve for a rapidly decreasing $\mathrm{pH}$. The growth curves increase with pressure in a sequential order. The simulation parameters that are common for all of the figures: $\alpha=3, \beta=2$

growth (Pietruszka 2012) can be relevant in the higher order of approximation. Moreover, the periodically elevated turgor pressure $P$ by a small $\delta P(t)$ amount (Benkert et al. 1997) can reflect the viscoelastic/viscoplastic dynamic transitions caused by minute (but many) $\mathrm{pH}$ changes similar to the one
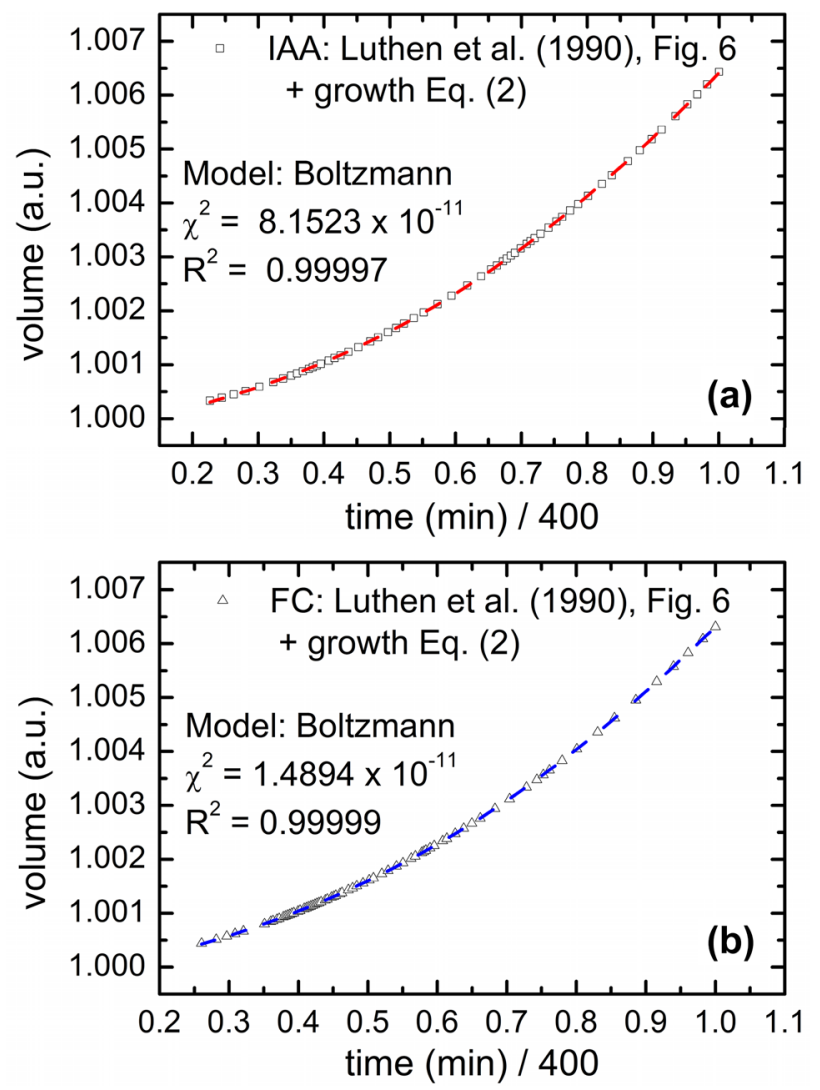

Fig. 8 Effect of an external decrease of $\mathrm{pH}$ on the accelerated phase of the expanding volume of maize coleoptiles as obtained by the $\mathrm{pH}$ drops that were induced by $10^{-5} \mathrm{M}$ IAA (A) and $10^{-6} \mathrm{M} \mathrm{FC} \mathrm{(B)} \mathrm{in}$ an experiment conducted by Lüthen et al. (1990). Squares and triangles-converted (recalculated) separately (point by point) using Eq. (21) from the digitised data presented in Fig. 6 by Lüthen et al. (1990); dashed curves-sigmoid curve (Boltzmann) fit (Microcal Origin). Conversion data: $\alpha=3$ and $\beta=2$. Simulation parameters: $T=0.62\left(\sim 26^{\circ} \mathrm{C}\right)$ and $P-P_{c}=0.3 \mathrm{MPa}$

presented in the inset to Fig. 9-leading to macroscopic pollen tube oscillations.

Note that Eq. (20) guarantee that the maximum growth rate is for the maximum of beta $f(\alpha, \beta, T)$ function. It is also evident that oscillations of $\mathrm{pH} \approx \sin (\Omega \cdot t)$ will produce oscillations of the exponent function, however, shifted in phase like $\cos (\Omega \cdot t)$. This, in turn, can be responsible for-as yet unexplained-about $90^{\circ}$ phase shift observed by many authors (e.g. Messerli et al. 1999) in pollen tubes.

Calculation of the $\alpha$ and $\beta$ shape coefficients for the actual empirical data is commented below.

\section{Determination of the $a$ and $\beta$ Shape Coefficients for Experimental Data}

Potential applications of the presented formalism lie in the $\alpha$ and $\beta$ parameters and the direct use of $\mathrm{pH}(\mathrm{t})$ data in calculating the volume increase $\mathrm{d} V$. However, in Eq. (21), one 


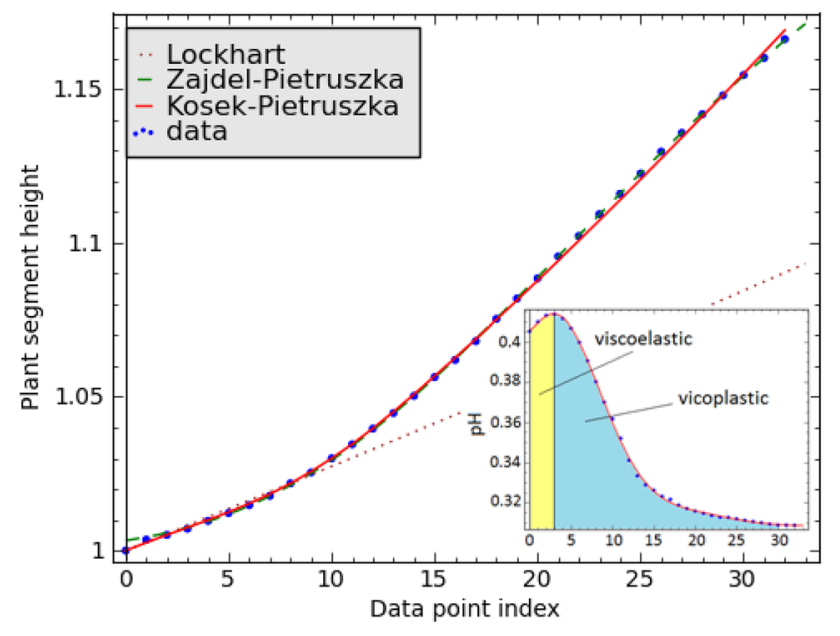

Fig. 9 Effect of a decrease in $\mathrm{pH}$ on the elongation growth of a maize coleoptile segment. Inset blue dots-discrete data from our APWdriven experiment (acid growth), red line-interpolation by a polynomial of the $5^{\text {th }}$ order. Main chart Orange dotted line-Lockhart (1965); green dashed line-experimental values (blue dots) interpolated by a double-exponent function (Zajdel et al., 2016); red linecalculated numerically from Eq. (21). Simulation parameters: $T=0.6$ $\left(\sim 25^{\circ} \mathrm{C}\right)$ and $P-P_{c}=0.3 \mathrm{MPa}$; data point index corresponding to $15 \mathrm{~min}=900 \mathrm{~s}$ intervals; [1] $=10 \mathrm{~mm}$ in the vertical scale. An example of the direct use of the $\mathrm{pH}(t), P, T \stackrel{\alpha, \beta}{\longrightarrow} V(t)$ conversion (no lag phase, corresponding to acid growth) for the increasing volume of a plant cell (provided the segment cross-section area is included) in the dark. Note the inflection point in both curves. Inset Usual representation of the $\mathrm{pH}$ versus time plot. A new interpretation of the characteristic maximum in $\mathrm{pH}$ is indicated in the plot: the viscoelastic/viscoplastic transition point $(\approx 3)$ creating typical curvature (change in the slope at the abscissa $\approx 3$ ) in the main chart. The program in SAGE solving Eq. (21) for experimental data may be delivered under reasonable request (Color figure online)

obtains $\exp (f(\alpha, \beta, c) \times$ integral $(\alpha, \beta))$ dependence—such problems have several local extremes. Therefore, the solution of Eq. (20) belongs to the class of highly non-linear optimisation problems and will be presented in a separate paper.

I suppose that the biological meaning of the $\alpha$ and $\beta$ shape exponents that is not discussed here may acquire connotation for more abundant sets of data. Nonetheless, it seems that Eq. (21) can be treated as the transformation $\mathrm{pH}(t), P, T \stackrel{\alpha, \beta}{\longrightarrow} V(t)$ for the increasing volume of a plant cell (corresponding to the $\mathrm{pH}$-driven cell enlargement).

\section{Monotonic Cell Elongation}

In order to check the Ansatz, which is expressed by Eq. (20), I also examined the decreases of $\mathrm{pH}$ that were induced by auxin (IAA) and fusicoccin (FC) in Lüthen et al. (1990), which is presented in Fig. 6 therein. There, the additions of IAA and FC resulted in rapid drops of $\mathrm{pH}$. The authors asserted that these lower $\mathrm{pH}$ values are responsible for the rapid increase in the growth rate. I digitised the $\mathrm{pH}$ data that were presented by Lüthen et al. (1990) and inserted these (point by point) into Eq. (21) separately. As a result, I received two fragments of growth curves, which are presented in Fig. 8. Note that to determine the cell volume evolution over time, we only needed the values of the following dynamic variables: $\mathrm{pH}$, temperature and turgor pressure; the initial volume $V_{0}$ was needed for scaling; $T=$ const. and $P \approx$ const. though the latter may also change in time. Interestingly, the simulation data for the $\alpha$ and $\beta$ parameters, which represent the properties of the wall, were adapted by combining the EWS with the evolution Eq. (21). These data, for which Eq. (21) is not divergent (unlike the Lockhart equation), closed the "system of equations" for growth. By the "system", I mean (a) the EWS, which describes the properties of the cell wall irrespective of the extension mechanism and (b) the equation of time evolution, Eq. (21), which describes the dynamics of the growing system at temperature $T$ (see also Pietruszka, 2012). Moreover, the direct use of Eq. (21) to our own experimental data is presented in Fig. 9, where $\mathrm{pH}(t), P$ and $T$ transform directly into the elongating height (volume $V$ ) of a plant tissue (note the correctly determined initial value of 1 ).

In this paragraph, I demonstrated that Eq. (21) correctly describes monotonic growth in the context of the "acid growth hypothesis" (note that $\mathrm{pH}$ is explicitly included in this equation; see also Figs. 8 and 9 and Eq. (9) in Pietruszka and Haduch-Sendecka (2016) and the conclusions therein), which validates its applicability not only for fusicoccin, but also for auxin (Hager 2003). The high accuracy of the theoretical fits (solid lines) with those that originated experimentally (Fig. 6 in Lüthen et al. 1990) or especially to the data, which is presented in Figs. 8 and 9 , respectively, strongly support the presented approach. However, the question about the potential applicability of Eq. (21) to oscillatory growth still remains.

\section{Periodic Cell Elongation}

The $\mathrm{pH}$ value is a logarithmic measure of the tendency of a solution to take $\mathrm{H}^{+}$in aqueous solutions. Yet, $\mathrm{pH}$ can be directly expressed in terms of the chemical potential $\left(\mu_{\mathrm{H}+}\right)$ through the relation

$\mathrm{pH}=\log _{10}\left[\exp \left(-\frac{\mu_{\mathrm{H}^{+}}-\mu_{\mathrm{H}^{+}}^{0}}{R T}\right)\right]$

where $R$ denotes the gas constant and $\mu_{\mathrm{H}^{+}}^{0}$ is the reference potential. $\mathrm{pH}$ is not a typical generalised coordinate, although the microscopic state of the system can be expressed through it in a collective manner. Just as temperature determines the 
flow of energy, the chemical potential determines the diffusion of particles (Baierlein 2001).

After inserting Eqs. (24) into (21), one can calculate the influence of the chemical potential oscillations of $\mathrm{H}^{+}$ions, $\mu_{\mathrm{H}+}=\mu_{\mathrm{H}+}(t)$, on the volumetric expansion. A simplistic numerical simulation reveals that the volumetric expansion represents a typical growth (sigmoid) curve (like the one presented in Fig. 6b). However, in this case, when superimposed onto the simulated oscillations of the chemical potential, they produce the growth rate oscillations in a straightforward manner (Pietruszka and Haduch-Sendecka 2015a). This type of oscillations was observed in the rapid expansion of pollen tubes (Plyushch et al. 1995; Hepler et al. 2001; Feijo et al. 2001), and the source of this periodic motion has been the subject of a long-lasting debate among plant biologists. Portes et al. (2015) noted that "Since the ultradian rhythms present in pollen tubes are not temporally coincident with protein synthesis and degradation, a simpler mechanism might be triggering the overall oscillation". Further, the authors claimed that "the strongest candidates seem to be the membrane trafficking machinery and ion dynamics, since they are the only candidate mechanisms that may oscillate independently of tube extension (Parton et al. 2003)". Indeed, in what follows a chemical potentialinduced (ultimately connected with ion dynamics since it measures the tendency of particles to diffuse) recurrent model, which triggers the overall oscillation, is proposed to explain this oscillatory mode of a single cell extension.

\section{Discussion}

The physicist Erwin Schrödinger (1944) may have been the first to consider the thermodynamic constraints within which life evolves, thereby raising fundamental questions about organism evolution and development. Here, it was attempted to present a more modest description in terms of the EWS and methods such as the calculations of critical exponents. More precisely, this work seeks to model the relationship between plant growth and temperature (or $\mathrm{pH}$ ), thereby describing growth optima as functions of the state variables and critical exponents. Apparently, there is already a simple and compelling explanation for the growth optima of plant growth from the biological point of view. Growth is mediated both directly and indirectly by enzymes and increases broadly in line with the frequently observed effect of temperature on enzyme activities (Berg et al. 2002). However, once temperatures are sufficient to denature proteins, enzyme activities rapidly decrease and plasma membranes and some other biological structures also experience damage (compare SI Fig. $1 b$ at a high temperature end).

\section{Sensing Structural Transitions}

A magnitude that infinitesimal changes result in symmetry change always exists in physics in continuous phase transitions (Landau and Lifshitz 1980). However, structural changes such as the ones considered here usually take place in non-equilibrium conditions (Racz 2002). Seemingly, such (order/disorder) symmetry changes (De Gennes 1991) in biological systems may be connected with a mechanism (Rojas et al. 2011) by which chemically mediated deposition causes the turnover of cell wall cross-links, thereby facilitating mechanical deformation. It may also reflect the pectate structure and distortion that was suggested by Boyer (2009) (Fig. 5c, d) in Chara cell walls by placing wall polymers in tension and making the load-bearing bonds susceptible to calcium loss and allowing polymer slippage that irreversibly deforms the wall. Proseus and Boyer (2007) suggested that a ladderlike structure would be susceptible to distortion and that the distortion would increase the distance between adjacent galacturonic residues (Fig. 5d in Boyer 2009), and therefore, the bonds may lengthen and thus weaken and decrease their affinity for $\mathrm{Ca}^{2+}$. Dissociation may then occur, thus allowing an irreversible turgor-dependent expansion (see also Fig. 4 in Pietruszka 2013; this is also applicable for non-isochronous growth in pollen tubes). The direction of the maximal expansion rate is usually regulated by the direction of the net alignment among cellulose microfibrils, which overcomes the prevailing stress anisotropy (Baskin 2005). However, the organisation of cellulose microfibrils depends on the organisation of the cortical microtubules (Paredez et al. 2006), which is modified by many different factors such as mechanical stimuli, light or hormones (Fishel and Dixit 2013). These modifications are regulated via DELLA proteins (Locascio et al. 2013) and/or arabinogalactan proteins (Willats and Knox 1996; Marzec et al. 2015b). The transient changes in the wall composition and the deformation of bonds may be a hallmark of symmetry change and a kind of ST (orchestrated instability) that is taking place in the cell wall.

The cell wall is supplied with the precursors of polysaccharides and also some proteins through exocytosis. This process is a form of active transport in which a cell transports molecules out of the cytoplasm into the extracellular matrix or intracellular space by expelling them in an energy-using process. Endocytosis is its counterpart. The loaded vesicles are transported by kinezine through microtubules into the plus end while by dinezine towards the minus ends, and ATP is utilised in both binding and unbinding processes of the motors heads. Besides microtubules, the actin cytoskeleton represents the most demanding energy-using process. In fact, in plant cells, both exocytosis and endocytosis are F-actin dependent processes that are 
related to cell wall assembly and maintenance. Moreover, there is strong evidence that plant cell elongation itself also depends on motors actin cytoskeleton rearrangement, see a series of studies by Baluška et al. (1997), (2001), (2002) and Wojtaszek et al. (2007). Indeed, these energy-consuming processes are apparently not included in the EWS.

A situation that was already pointed out in the Introduction in which the protons that are excreted into the wall compartment are directly responsible for the wall-loosening processes through the hydrolysis of covalent bonds or the disruption of non-covalent bonds may also be a signature for the symmetry change and STs that occur in the wall compartment of the growing cell. Though the underlying microscopic mechanisms are not well recognised as yet (and as a result the order parameters are difficult to identify - tethers 'melting' from the attached to detached state against $\mathrm{pH}$ or $T$ can be a first candidate, Sridhar et al. 2018), a pH-driven "lambda" ST may be attributed to the maximum activity of $\mathrm{PM} \mathrm{H} \mathrm{H}^{+}$-ATPase, while temperature-driven STs in the cell wall can be directly related to the maximum elevation of the effective diffusion rate $\left(k_{2}\right.$ coefficient in Pietruszka 2012)—it was considered primary (diffusive) growth throughout this article. As an aside, from the calculation of cross-correlations, we may draw further conclusions that are connected with the biochemical picture of the acid growth theory. The result presented in SI Fig. 3 is a clear characteristic that temperature-induced growth and auxin-induced acidification ( $\mathrm{PM} \mathrm{H}^{+}$-ATPase) growth correlate strikingly well (there is good experimental evidence that a higher temperature induces auxin biosynthesis in some plants). However, the convolution of acidic $\mathrm{pH}$ growth and temperature growth is less shifted away from zero (lag) and is even more pronounced; see also recent outcomes in Pietruszka and Haduch-Sendecka (2016) as well as Olszewska et al. $(2017,2018)$ for cell wall $\mathrm{pH}$ (proton efflux rate) and growth rate, which are directly co-regulated in growing shoot tissue, thus strongly supporting the empirical foundations of EWS. Even more supportive for the EWS-model is the result obtained by Damineli et al. (2017), where the extracellular $\mathrm{H}^{+}$flux and growth rate curves practically overlap (see Fig. $2 \mathrm{~d}$ therein); the periods $(47.7 \pm 3.2 \mathrm{~s}$ and $48.7 \pm 4.3 \mathrm{~s}$, respectively) for both processes are almost identical within experimental error. This strict quantitative result may contribute to the acid growth hypothesis that was developed by plant physiologists and make a contribution to resolving the problems that occur in the long-lasting discussion. However, a problem still arises. It is unclear to what degree Eq. (5) applies universally as the published raw data that constitute the experimental basis are only for grass shoot elongation growth. The long-standing acid growth theory postulates that auxin triggers apoplast acidification, thereby activating the cell wall-loosening enzymes that enable cell expansion in shoots. This model remains greatly debated in roots.
However, recent results (Barbez et al. 2017) in investigating apoplastic $\mathrm{pH}$ at a cellular resolution show the potential applicability of Eq. (5) for roots.

\section{Migration of Plants}

I now show that my findings may be embedded in the evolutionary context that is connected with the migration of plants away from the Equator (with changes in latitudes) as the climate changed as well as their adaptation to the spatial distribution of $\mathrm{pH}$ in the soil as a substitute for a high temperature. As an example that exhibits the capabilities of Eq. (5), let us consider the following. The dominant factors that control $\mathrm{pH}$ on the European scale are geology (crystalline bedrock) in combination with climate (temperature and precipitation) as was summarised in the GEMAS project account (Fabian et al. 2014). The GEMAS pH maps primarily reflect the natural site conditions on the European scale, while any anthropogenic impact is hardly detectable. The authors state that the results provide a unique set of homogeneous and spatially representative soil $\mathrm{pH}$ data for the European continent (note Fig. 5, ibid.). In this context, the EWS that is expressed by Eq. (5) may also have an evolutionary dimension when considering the spatial distribution of $\mathrm{pH}$ data as affected by latitude (angular distance from the Equator) elevation on the globe, which is associated with climate reflection (ibid.). $\mathrm{pH}$ is strongly influenced by climate and substrate- the $\mathrm{pH}$ of the agricultural soils in southern Europe is one $\mathrm{pH}$ unit higher than that in northern Europe. See also Fig. 4 in Fabian et al. (2014) in which the $\mathrm{pH}\left(\mathrm{CaCl}_{2}\right)$ of soil samples that are grouped by European climate zones are measured (descending from $\mathrm{pH} 7$ (Mediterranean), $\mathrm{pH} 6$ (temperate) through $\mathrm{pH} 5.25$ (boreal) to $\mathrm{pH} 4.80$ (sub-polar)). This fact may be reinterpreted in terms of the $\mathrm{pH}$-temperature duality that is considered in this work. When the migration of plants away from the Equator occurred, lower $\mathrm{pH}$ values further to the North might have acted in a similar way on the growth processes as high temperatures in the tropic zones. This situation could have led to energetically favourable mechanisms (adaptation) such as the amplified ATP-powered $\mathrm{H}^{+}$extrusion into the extending wall of plant cells and the secondary acidification of the environment (released protons decrease $\mathrm{pH}$ in the incubation medium), irrespective of the initial $\mathrm{pH}$ level, which is the main foundation for the acid growth hypothesis. Apparently, the evolutionary aspect of Eq. (5), which suggests a possible link with self-consistent adaptation processes, as one of its first applications, seems difficult to underestimate, and the potentially predicative power of EWS looks remarkable considering the modest input that was made by deriving Eq. (5). In this perspective, the $\mathrm{pH}$-response could potentially provide a plant with an adaptive advantage under unfavourable climate conditions. Together with the discovery of 
Table 1 Preliminary data for $\alpha$ and $\beta$ exponents for maize (Zea mays L.) and wheat (Triticum vulgare Vill.), which belong to the same family Poaceae but to different subfamilies: Panicoideae and Pooideae, respectively; the calculated values for $\alpha$ and $\beta$ are similar

\begin{tabular}{lllll}
\hline Clade & Monocotyledons & & Dicotyledons \\
\hline Species & Zea mays L. & Triticum vulgare Vill. & Phaseolus vulgaris L. & Cucurbita pepo L. \\
$\alpha$ & $2.88 \pm 0.3$ & $2.91 \pm 0.5$ & $2.58 \pm 0.6$ & $5.5 \pm 1.1$ \\
$\beta$ & $4.77 \pm 0.5$ & $3.88 \pm 0.7$ & $4.3 \pm 1.0$ & $11.1 \pm 2$ \\
\hline
\end{tabular}

The common bean (Phaseolus vulgaris L.) and cucurbita (Cucurbita pepo L.) belong to the same clade Eudicots but to different orders: Fabales and Cucurbitales, respectively; the calculated values for $\alpha$ and $\beta$ differ significantly. The calculation that is based on Fig. 1 in Lewicka and Pietruszka (2008) and SI Eq. (1). Table courtesy of my PhD student Aleksandra Haduch-Sendecka

the function of phytochromes as thermosensors (Jung et al. 2016), the EWS could be useful in breeding crops that are resilient to thermal stress and climate change.

\section{Classes of Universality}

The EWS for a biological system has not been reported until this study. To further verify the EWS and its implications, it was noted that based on the results that were obtained (the calculated critical exponents), a kind of universality hypothesis (Stanley 1971) can be tested experimentally in order to extract "classes of universality" for plant species $\left(\Omega_{\mathrm{S}}\right)$, thereby substantiating the taxonomic divisions in the plant kingdom via quantitative measures (Table 1). This issue, which may be called "extended plant taxonomy" (similar to "dimensionless numbers" proposed by Ortega 2018 for Plant Biology), demands further experimentation and is beyond the scope of this theoretical work.

\section{Further Perspectives}

It seems the EWS may explain a number of phenomena and is powerful in its simplicity. It positions itself at the brink of biology and nano-materials. It may be helpful in identifying the processes of the self-assembly of wall polymers. In agricultural implementations, any departures from the optimum growth may simply be corrected by appropriately adjusting $\mathrm{pH}$ or $T$.

The finding of the EWS for plants adds an significant dimension in the biophysical search for a better explanation of growth-related phenomena in a coherent way through its applicability to the viscoelastic (or viscoplastic) monotonically ascending and asymptotically saturated (Pietruszka 2012) cell wall extension that is usually observed, as well as to pollen tube oscillatory growth. The underlying biochemical foundation, which is expressed in the form of the acid growth hypothesis, could also help to understand the growth conditions that are ubiquitous in biological systems through coupling to EWS. In this respect, the presented method is accompanied by its partial validation-its application to the important biological question concerning the acid growth hypothesis. In the above context, it is not surprising that the growth of the cell wall in plants can be thought of as a timedriven series of STs (via the breaking of polymer bonds or other mechanisms that were mentioned earlier), although they are ultimately connected with the physical conditions and chemistry by the Eqs. (5) or (6b). Since non-equilibrium stationary states, which always carry some flux (of energy, particle, momentum, information, etc.), are achieved after discrete intervals of time for single cells such as pollen tubes, such a (chemical potential ratchet) mechanism can lead to a kind of leaps in the macroscopically (of $\mu \mathrm{m}$ scale) observed growth oscillations (Geitmann and Cresti 1998; Hepler et al. 2001; Zonia and Munnik 2007). Similar mechanisms were observed in multicellular models for plant cell differentiation such as rhizodermis (Marzec et al. 2013a) where the growth of root hair tubes occurs by leaps and bounds (Vazquez et al. 2014). This phenomenon may be treated as the final result of the subsequent STs that take place in the cell wall.

On the other hand, spontaneous bond polarisation/breaking may be synchronised through Pascal's principle by pressure $P$ or pressure fluctuations $\delta P$ (Pietruszka and Haduch-Sendecka $2015 \mathrm{a}$ ), thereby acting as a long-range (of the order of $\xi$ ) messenger at the state change (the radius of coherence $\xi \rightarrow \infty$ at a $\Gamma$-interface in Pietruszka 2013). When the entire system is correlated and the stress-strain relations are fulfilled (ibid.), the simultaneous extension of the cell wall at the sub-apical region may correspond to pollen tube oscillation(s). Hence, an uncorrelated or weakly correlated extension would result in the bending that is observed in the directional extension of the growing tube. In multi-cell systems (tissues) that have a higher organisation (coleoptiles or hypocotyls in non-meristematic zones), the EWS for plants will manifest itself by the emergent action of an acidic incubation medium or will be induced by endogenous auxin acidification as is presumed in the acid growth theory. In this aspect, the EWS may serve as a new tool for the further investigation and verification of claims about the acid growth hypothesis (Barbez et al. 2017). This should greatly facilitate the analysis of auxin-mediated cell elongation as well as provide insight into the environmental regulation of the auxin metabolism.

It is important to note that "Cellular growth in plants is constrained by cell walls; hence, loosening these structures 
is required for growth. The longstanding acid growth theory links auxin signalling, apoplastic $\mathrm{pH}$ homeostasis, and cellular expansion, providing a conceptual framework for cell expansion in plant shoots. Intriguingly, this model remains heavily debated for roots" (Barbez et al. 2017). The authors' findings permitted the complex involvement of auxin in root apoplastic $\mathrm{pH}$ homeostasis to be elucidated, which is important for root cell expansion, and shed light on the acid growth mechanism in roots. This is, in turn, the outcome of the model equations, which are apparently applicable for elongating roots (root hair), shoots or even a single plant cell (pollen tube).

Moreover, by using the EWS, it will be possible to answer the question about role of the crosstalk between auxin and other hormones such as strigolactones (Marzec and Muszynska 2015), in growth of plant cells. It also seemingly delivers a narrative that provides a biophysical context for understanding the evolution of the apoplast, thereby "uncovering hidden treasures" in the as yet unscripted biophysical control systems in plants.

Summarising, I took a physical approach to plant growth to simplify the universal features that may explain the observations. I have fitted a simple algebraic function (a beta Euler function) to some growth rate data, thus capturing the variations with respect to temperature and $\mathrm{pH}$, which show a surprisingly conjugate nature. Cross-disciplinary research at the interface between the physical and life sciences was accomplished. I first considered the Euler beta function enigma, which is the duality of acidic $\mathrm{pH}$ (or auxin-induced acidification) and temperature, in order to obtain the EWS for a living system. I started from the striking similarity (mirror symmetry) between the elongation growth of the grass shoots that were incubated in different $\mathrm{pH}$ environments or auxin-induced elongation in water (or a neutral buffer) with the respective growth at different temperatures. These observations were based on the hypothesis that the effect of temperature on elongation growth is effectively equivalent for the relative growth increments such as those that are caused by a change of $\mathrm{pH}$ or endogenous auxininduced acidification in the incubation medium. In order to resolve this ambiguity, I first used the beta function for both dependences, which were normalised prior to the comparison, in order to obtain the beta function shape parameters $\alpha$ and $\beta$. It turned out that even without referring to the biochemical underpinning, one might have concluded that the acidic conditions of the incubation medium or auxininduced acidification and environmental temperature can act interchangeably, at least when they are considered at a phenomenological (mechanistic) level. The numerically verified high accuracy of these complementary representations allowed us, among others, to treat this dual approach as a new apparatus for predicting the outcomes in different growth conditions, which is especially useful in changing climate environments. I presumed that by applying a beta distribution and continuously changing its character with the values of the shape parameters, our findings might be related to the evolutionary context that is connected with the migration of plants away from the Equator as the climate changed and their adaptation to the spatial distribution of $\mathrm{pH}$ in the soil as a substitute for high temperatures. The EWS may be also helpful in delivering analytical solutions (the respective $\left(\alpha, \beta, \Omega_{\mathrm{S}}\right)$-triads) for the assisted migration of plant species (Vitt et al. 2010) that are at the risk of extinction in the face of rapid climate change. In this application, the EWS tool can constitute a complementary method for genetic modifications in the assisted migration processes by permitting the best species to be selected for such an introduction from those having a similar (to within experimental error) triad.

\section{Application of Critical Exponents}

In physics, it is believed (Fisher 1966; Griffiths 1970) that the critical exponents are "universal", i.e. independent of the details of the Hamiltonian (energy function) that describes a system. The implications of these, however, are far reaching. One could take a realistic and complicated Hamiltonian, 'strip' it to a highly idealised Hamiltonian and still obtain precisely the same critical exponents. For instance, on these grounds, it is believed that carbon dioxide, xenon and the three-dimensional Ising model should all have the same critical exponents (Baxter 1989) and this appears to be the case (Hocken and Moldover 1976). In this context, since growth phenomenology (non-equilibrium orderings) and the STs approach have converged to a form an EWS for plants, the potential role of the critical exponents in discriminating the different modes of the wall extension (Breidwood et al. 2014 for review) of growing cells or tissues seems promising in opening new avenues of research.

\section{Chemical Potential-Induced Ratchet-Like Growth in Plants}

It is known that the group of oscillating variables during growth includes at least ion fluxes (Sukhov et al. 2011) and internal free concentrations of $\mathrm{Ca}^{2+}, \mathrm{Cl}^{-}, \mathrm{H}^{+}$and $\mathrm{K}^{+}$ions (Holdaway-Clarke et al. 1997; Holdaway-Clarke and Hepler 2003), the cytoskeleton (Geitmann 2010), membrane trafficking (Feijó 1999; Feijo et al. 2001; Zonia and Munnik 2008) and cell wall synthesis (see Portes et al. 2015 and Hemelryck et al. 2017 for review). However, despite the progress made in this domain, the central core-controlling mechanism is missing (Damineli et al. 2015). Moreover, how it produces a macroscopic outcome in the form of apical growth also remains uncertain. A possible link between this oscillatory component at the molecular level and the 


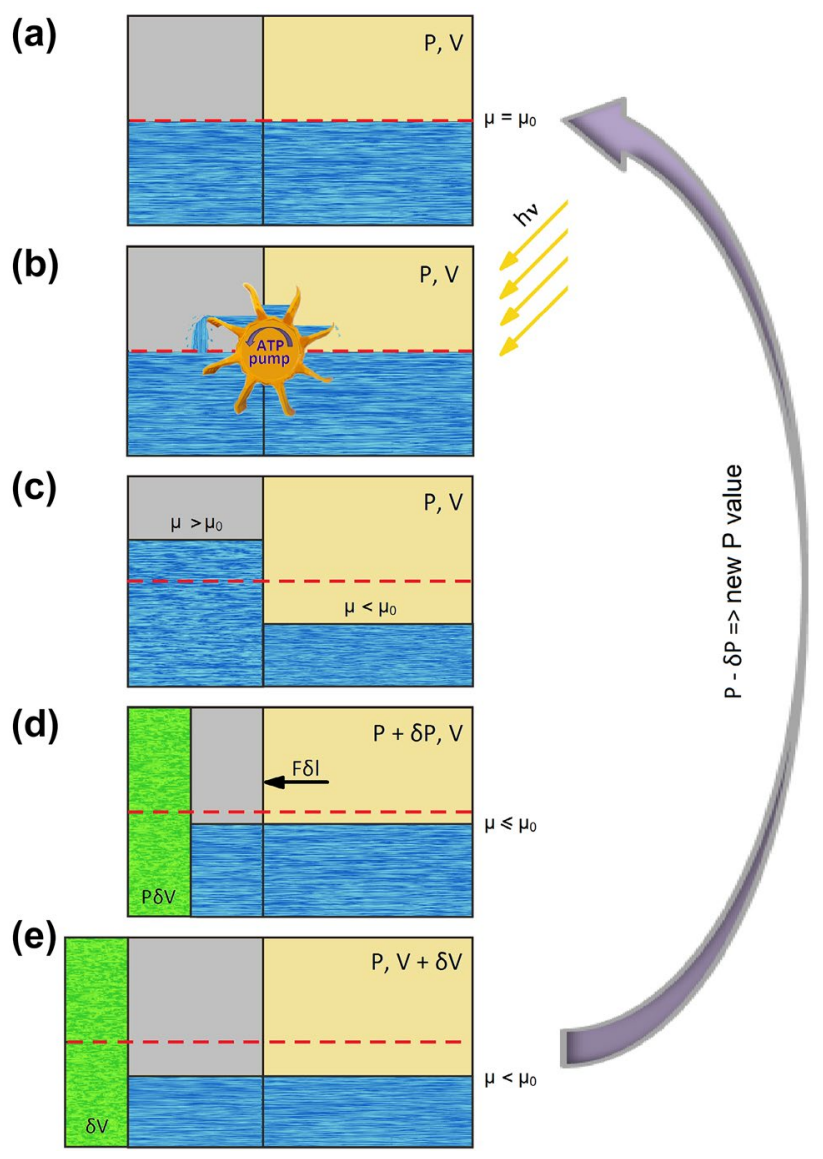

Fig. 10 Plant cell expansion recurring model-a proposal. a Initial state: the chemical potential $\mu$ ( $\mu_{0}$ - reference potential) equilibrated in both compartments; turgor pressure equals $P$; cell volume equals $V$. b Energy-consuming proton pump driven by the hydrolysis of ATP transports protons (ions) against the electrical gradient. c Chemical potential difference is established between the compartments-the system is far from equilibrium; turgor pressure equals $P$; cell volume $V$. d Synthesis of cellulose at the plasma membrane and of the pectin and hemicelluloses components with a Golgi apparatus depositing a layer on the inside of the existing cell wall, thus causing an increase of the cytoplasm pressure by the infinitesimal value of $\delta P: P+\delta P(t)$, though the cell volume still remains $V$. d New wall synthesis. Elevated turgor pressure $P$ by a $\delta P(t)$ amount (Benkert et al. 1997) produces force $F$, which acts on the wall (energy stored equals $P \delta V$ ). The chemical potential starts to drop due to the overall particle loss in the system. e Increasing turgor pressure releases energy to extend the existing cell wall chamber by $\delta l$; the chemical potential further decreases before the next cycle (arrow). After the completed growth cycle, turgor pressure diminishes by the $\delta P(t)$ value due to leakage or the other mechanisms illustrated in the text. Another growth cycle begins (arrow), however, with a new initial value of $P$ equal to $P$ $\delta P(t), V$ equal to $V+\delta V$ and $\mu$ equal to $\mu-\delta \mu$ (exaggerated). Legend Left compartment: plasma membrane (PM) and cell wall. Right compartment: cytoplasm. Grey-PM, blue- $\mathrm{H}^{+}$-"Fermi sea", greennew cell wall (Color figure online)

structurally (spatial arrangement) and temporally organised apical (periodic) growth is described below.

Indirect measurements of the chemical potential $\left(\mu_{\mathrm{H}+}\right)$ using $\mathrm{pH}$ can be compared to our previous measurements of the electromotive force (EMF) in order to detect phase transitions, which are localised by the 'kinks' in the chemical potential in condensed matter physics (Matlak and Pietruszka 2001; Matlak et al. 2001). Such kinks in the chemical potential always localised the occurrences of different types of phase transitions (where the change of state of a macroscopic system occurs) such as ferromagnetic, anti-ferromagnetic, superconducting, re-entrant or structural phase transitions (Matlak et al. 2000). Based on these observations and considerations on the EWS for plants, one can combine these outcomes together in a single coherent account.

Launching reasoning from the EWS and putting the differing approaches that were outlined in the Introduction together, a plant cell expansion recurring model can be assembled. The latter, though unsophisticated for obvious reasons, not only describes one cell growth cycle in physical (mechanistic) terms, but also demonstrates how subsequent growth cycles can arise and even how the entire process may eventually decay (compare with Rounds et al. 2010).

The hypothetical steps in the transport of cations (such as $\mathrm{H}^{+}$) against its chemical gradient by an electrogenic pump and its consequences are presented in Fig. 10 and SI Figs. 4, 5,6 . These can be described as follows:

A. The initial state of a growing cell (I assume the chemical potential $\mu=\mu_{0}$ for reference only).

B. The outward, active proton transport across the plasma membrane interface creates gradients of $\mathrm{pH}$ or equivalently gradients of the chemical potential $\mu=\mu_{\mathrm{H}+}$, which drives the transport of ions and uncharged solutes. The plasma membrane (marked by a vertical line) depicts the boundary between the cell wall and the cytoplasm.

C. $\mathrm{H}^{+}$-ATPase activity regulates cytoplasmatic $\mathrm{pH}$ (and controls cell turgor pressure). At the microscopic level, we can observe a singular behaviour at a certain critical value of the chemical potential $\mu=\mu_{\mathrm{c}}$ (see also Fig. 5c). This chemical potential activity can be interpreted as a signature for an ST that is occurring in the cell wallduring an ST of a given medium, certain properties of the medium change, often discontinuously, as a result of a change in some condition, here: $\mu$.

D. The increased involvement of $\mathrm{H}^{+}$ions in cell wall building and exocytosis (Holdaway-Clarke and Hepler 2003) by $\delta V$ raises the turgor pressure inside the cell by $\delta P$, thus producing force $F$, which may cause cell wall loosening and elongation by $\delta l$ (see Wei and Lintilhac 2007 for a loss of stability approach and Sridhar et al. 2018 for a statistical model of expansive growth). The physical quantity that may be responsible for signal transduction here is pressure (e.g. Zonia 2010), which is a scalar quantity.

E. The increased pressure at the apical plasma membrane by $\delta P$ induces the stress relaxation of the cell wall, 
relaxation-driven cell expansion by $\delta V$ and triggers the start of the next growth cycle with a slightly modified turgor pressure $\sim P-\delta P$ (see the linearly descending pressure plotted in Fig. 1 in Benkert et al. 1997). The system restores the initial configuration and allows a new growth cycle to begin (explicit in pollen tube oscillations). The latter means it is reset at the end of the cycle (Hemelryck Van et al. 2018).

As a result, the problem of causality, which was mentioned in the Introduction, is proposed to be resolved in a self-consistent manner, thus potentially leading to a paradigm change that can be expressed by a self-consistently evolving recurring model. Obviously, the latter should be further examined by numerical calculations (self-consistent solutions at subsequent time intervals) and confronted with the existing representations (Baskin 2015, see Fig. 1.1 therein for a complementary Maxwell-type model). The possible mechanisms of the participation of $\mathrm{pH}$ changes on photosynthesis (Grams et al. 2009; Sukhov et al. 2014; Sherstneva et al. 2015; Sukhov et al. 2016) can also be included in the form of a phase-locked loop, thus closing the 'system of equations'. The existence of oscillating behaviours in the investigated system, however, implies the existence of a control by feed forward or feedback loops, which are inserted into a self-regulating mechanism (Portes et al. 2015). The latter statement can be translated in mathematical terms into a self-consistent time evolution equation that corresponds with growth.

\section{The Recurrent Model}

Let us briefly discuss the major novelty of the recurrent model as compared to the earlier work in the context of the previous models. The main approaches that were outlined in the Introduction emphasised a single attribute that is responsible for expansion (or periodic) growth. However, it seems that none of these factors alone (such as oscillatory wall synthesis, excessive turgor pressure or turgor pressure oscillations) can explain all of the observable modes of cell expansion and growth. Moreover, because of the intricate dependence between the processes that are involved in tip growth, causal relations cannot be easily inferred solely from phase relations (Pietruszka and Haduch-Sendecka 2015b) as simultaneous information about the role of the participating ions and the actual growth rate amplitude are required.

\section{Pollen Tube Growth and Oscillations}

Furthermore, intracellular ion dynamics has been shown to play an essential role in pollen tube growth (Portes et al. 2015), while calcium, protons and chloride are also considered to be of major importance. Because the $\left[\mathrm{Ca}^{2+}\right]_{i}$ pool at the apex oscillates, it has also been considered as supporting growth (Messerli and Robinson 1997). Additionally, it has been experimentally verified that pollen tubes stop growing when the $\left[\mathrm{Ca}^{2+}\right]_{\mathrm{i}}$ gradient is dissipated (Pierson et al. 1994). An interesting fact regarding chloride dynamics is that in contrast to $\mathrm{Ca}^{2+}$ and $\mathrm{H}^{+}$, the ionic fluxes occur in the reverse direction at the apex, thereby elevating the chemical potential gradients even further.

Protons have received much attention as they play a crucial role in pollen tube growth. Since water, which ionises spontaneously, is the major component of living cells, $\mathrm{H}^{+}$ ions are known to be involved in enzymatic activity, endo/ exocytosis and many other processes (Portes et al. 2015 for review). Therefore, $\mathrm{pH}$ inside cells has to be regulated in harmony with the growth phases (Messerli and Robinson 1998). It was found that pollen tubes showed an acidic domain that was located close to the membrane apex-the latter was present only during growth. In addition, the localisation of pollen-specific $\mathrm{H}^{+}$-ATPase provides evidence that indicates correlations with the proton extracellular fluxes and the acidic domain at the apex (Certal et al. 2008). It looks as though proton dynamics is involved in the mechanisms for maintaining the polarity that ensures pollen tube growth (Portes et al. 2015). Moreover, it has been established (Agudelo et al. 2016) that the pollen tube response is correlated with the conductivity of the growth medium under different $\mathrm{AC}$ frequencies, which is consistent with the notion that the effect of the field on pollen tube growth may be mediated via its effect on the motion of ions. This is, however, in accord with the presented chemical potential ratchet scenario and the representative time series of the oscillatory traces of incoming cations $\left(\mathrm{H}^{+}\right.$and $\left.\mathrm{Ca}^{2+}\right)$ or outgoing anions $\left(\mathrm{Cl}^{-}\right)$at the growing tip. Hence, from the point of view of the recurrent model, the equilibration of the chemical potential for all of these species should also be the major mechanism for the cessation of growth. The ratchet scenario seems also compatible with tethers attachment/detachment/ reattachment dynamics in the molecular model proposed by Sridhar et al. (2018).

Ion homeostasis and signalling are crucial in regulating pollen tube growth and morphogenesis and affect upstream membrane transporters and downstream targets (Michard et al. 2016). Pollen tube growth is strictly dependent on ion dynamics. Ion fluxes and cytosolic gradients of concentration have been mechanistically associated with the action of specific transporters, especially protons. In the recurrent model I put forward, though extremely simplistic, $\mathrm{H}^{+}$chemical potential dynamics may serve as a "still missing" (Portes et al. 2015) central core-controlling mechanism or "pacemaker" that is able to produce a macroscopic outcome, i.e. structurally and temporally organised apical growth, especially since $\mathrm{H}^{+}$usually oscillates with the period similar to growth rate—see Fig. 2d in Damineli et al. (2017). 
On the other hand, the short period oscillations of $\mathrm{pH}$, which induce changes in wall properties, can be translated into the volume pulsatile extension by Eq. (20). Provided that cross-correlation (vs. time) of $\mathrm{pH}$ and $P$ exists, turgor pressure should vary slightly (Fig. 1 in Benkert et al. 1997) in accord with minute $\mathrm{pH}$ drops (note the pressure linear decrease); Eq. (20) allows for such analysis. This should also explain the observed phase delays in growth rate and ionic fluxes in pollen tubes in mechanistic terms (e.g. Messerli and Robinson 1998). This is, however, beyond the scope of this work and should be analysed in another study.

\section{Final Comments}

The aim of this work was to develop a unifying model to simulate plant cell expansion and growth. In the chemical potential representation, growth can be treated as a dynamic series of STs that can take place in the primary plant cell walls during subsequent time intervals. I suppose that such changes would proceed, e.g. from an ordered to disordered state, from a stressed to relaxed state, from a "covalent bonds state" to "disrupted covalent bonds state" or even through more subtle pathways in the wall polymer network, which themselves constitute an intriguing research task. Furthermore, the singular causality, whereby only biochemical wall loosening can lead to stress relaxation and turgor loss, is replaced by a self-consistent recurring model, in which all of the prevailing variables constitute the macroscopic evolution of the plant cell. A common denominator appears to emerge that ties all of the growth factors together, namely the chemical potential of intervening ions. [Oscillatory ion movement in the electrolyte solution (Pietruszka et al. 2018) accompanies the uni-directional increase in pollen tube, and changes the chemical potential (Fermi redox energy) of particular ions]. Further investigations can go along the lines clearly illustrated in Smithers et al. (2019).

At the beginning I asked, whether the volumetric growth of plants (in the dark) could be calculated from $\mathrm{pH}, T$ and $P$. It turned out that the answer is "yes", provided that it is delivered a posteriori, i.e. the $\mathrm{pH}$ growth data are already known. This reasoning, however, can be reversed-by knowing $\mathrm{pH}(t), T$ and $P$, one can precisely predict the cell volume $V$ expansion over time using model Eq. (21).

As we found out, from the physical point of view, cell volume expansion in plants follows the $\mathrm{pH}(t), P, T \stackrel{\alpha, \beta}{\longrightarrow} V(t)$ analytic transformation through the coupling between the mechanical (pressure), thermal (temperature) and chemical ( $\mathrm{pH}$ or $\mu$ ) degrees of freedom. In this process, the chemical potential of the intervening ions can play an important role-distant (non-local) correlations are no longer controlled externally, but by the system itself, which is similar to the self-organised critical states (Tang and Bak 1988; Bak et al. 1988; Hesse and Gross 2014; Pietruszka and Olszewska 2019) and remains in agreement with the statistical approach (viscoplastic and viscoelastic terms mapped onto a statistics of independently acting tethers, Sridhar et al. 2018) or recent opinion delivered by Mangano et al. 2018 concerning $\mathrm{pH}$ oscillations in pollens. Indeed, it has been suggested that a growing cell proceeds along a critical trajectory over $1 / f$ ridge (here $f$-fluctuation frequency of ionic channels), which is typical for regular growth (Pietruszka and Olszewska 2019; also Haduch-Sendecka et al. 2014 for the minimal energy loss in the natural growth conditions - a biological illustration of the principle of least action of Feynman and Hibbs 1965). The latter observation can be confirmed by the cross-correlations that are maximum for the control (normal) growth, see Figs. 4, 5 in Olszewska et al., 2018. Because of the $\mathrm{pH}(\mu)$ dependence, the signalling cascade during the growth of a cell seems to be triggered and controlled by the chemical potential of vital ions.

\section{Conclusions}

By resolving the duality of low $\mathrm{pH}$ or auxin action (producing acidic $\mathrm{pH}$ ) against temperature, not only it was introduced an EWS for the realm of plants, but also, by considering wall extension growth as a dynamic cascade of chemical potential driven STs, the critical indices (exponents) for this phenomenon were identified, which exhibit a singular behaviour at a critical temperature and critical $\mathrm{pH}$ in the form of power laws. This is concluded that the cell growth evolves along a path (trajectory) of the least action ('best-path'), thereby optimising growth under any physiological conditions. The inherent $\mathrm{pH}$ dynamics in close-to-natural conditions appears to essentially be responsible for this extreme trajectory, thereby providing a highly non-linear transformation $\mathrm{pH}(t), P, T \stackrel{\alpha, \beta}{\longrightarrow} V(t)$, where $V$ and $P$ stands for the volume and internal pressure of a cell, respectively. A common unifying principle that can be applied for either condensed matter (studied in physics) or living matter (a subject of biology) is proposed for all of the chemical potential-driven phase or state transitions, respectively.

Acknowledgements I thank dr Jerzy Kosek for the involvement in the numerical calculations in Fig. 9.

Author Contributions MP conceived the ideas, conducted the analyses, conducted the analytical and numerical calculations and estimates and wrote the manuscript.

Funding No Founder.

\section{Compliance with Ethical Standards}

Conflict of interest The authors declare no competing financial interests. 
Open Access This article is distributed under the terms of the Creative Commons Attribution 4.0 International License (http://creativeco mmons.org/licenses/by/4.0/), which permits unrestricted use, distribution, and reproduction in any medium, provided you give appropriate credit to the original author(s) and the source, provide a link to the Creative Commons license, and indicate if changes were made.

\section{References}

Agudelo C, Packirisamy M, Geitmann A (2016) Influence of electric fields and conductivity on pollen tube growth assessed via electrical lab-on-chip. Sci Rep 6:19812

Agusti J, Herold S, Schwarz M, Sanchez P, Ljung K, Dun EA, Brewer PB, Beveridge CA, Sieberer T, Sehr EM, Greb T (2011) Strigolactone signaling is required for auxin-dependent stimulation of secondary growth in plants. Proc Natl Acad Sci USA 108:20242-20247

Baierlein R (2001) The elusive chemical potential. Am J Phys 69:423-434

Bak P, Tang C, Wiesenfeld K (1988) Self-organized criticality. Phys Rev A 38:364-374

Baluška F, Vitha S, Barlow PW, Volkmann D (1997) Rearrangements of F-actin arrays in growing cells of intact maize root apex tissues: a major developmental switch occurs in the postmitotic transition region. Eur J Cell Biol 72:113-121

Baluška F, Jásik J, Edelmann HG, Salajov T, Volkmann D (2001) Latrunculin B induced plant dwarfism: plant cell elongation is F-actin dependent. Dev Biol 231:113-124

Baluška F, Hlavacka A, Šamaj J, Palme K, Robinson DG, Matoh T, McCurdy DW, Menzel D, Volkmann D (2002) F-actin-dependent endocytosis of cell wall pectins in meristematic root cells: insights from brefeldin A-induced compartments. Plant Physiol 130:422-431

Barbacci A, Lahaye M, Magnenet V (2013) Another brick in the cell wall: biosynthesis dependent growth model. PLoS ONE 8:e74400

Barbacci A, Magnenet M, Lahaye M (2015) Thermodynamical journey in plant biology. Front Plant Sci 6:1-7

Barbez E, Dünser K, Gaidora A, Lendl T, Busch W (2017) Auxin steers root cell expansion via apoplastic $\mathrm{pH}$ regulation in Arabidopsis thaliana. Proc Natl Acad Sci USA E4:884-E4893

Baskin T (2005) Anisotropic expansion of the plant cell wall. Annu Rev Cell Dev Biol 21:20322

Baskin TI (2015) Ultradian growth oscillations in organs: physiological signal or noise? In: Manusco S, Shabala S (eds) Rhytms in plants. Springer, Geneva

Baxter RJ (1989) Exactly solved models in statistical mechanics. Academic Press, Harcourt Brace Jovanovich, Publishers, Boca Raton

Benkert R, Obermayer G, Benturp F-W (1997) The turgor pressure of growing lily pollen tubes. Protoplasma 198:1-8

Berg JM, Tymoczko JL, Stryer L (2002) Biochemistry. Freeman \& Company, New York

Bidhendi A, Geitmann A (2016) Relating the mechanics of the primary plant cell wall to morphogenesis. J Exp Bot 67:449-461

Boudon F, Chopard J, Ali O, Gilles B, Hamant O, Boudaoud A, Traas J, Godin C (2015) A computational framework for 3D mechanical modeling of plant morphogenesis with cellular resolution. PLoS Comput Biol 11:e1003950

Boyer JS (2009) Cell wall biosynthesis and the molecular mechanism of plant enlargement. Funct Plant Biol 36:383-394
Breidwood L, Breuer C, Suigimoto K (2014) My body is a cage: mechanisms and modulation of plant cell growth. New Phytol 201:388-402

Certal AC, Almeida RB, Carvalho LM, Wong E, Moreno N, Michard E, Feijo JA (2008) Exclusion of a proton ATPase from the apical membrane is associated with cell polarity and tip growth in Nicotiana tabacum pollen tubes. Plant Cell 20:614-634

Cleland R (1971) Cell wall extension. Ann Rev Plant Physiol 22:197-222

Cleland R (1973) Auxin-induced hydrogen ion excretion from Avena coleoptiles. Proc Natl Acad Sci USA 70:3092-3093

Cosgrove DJ (1989) Characterization of long-term extension of isolated cell walls from growing cucumber hypocotyls. Planta 177:121-130

Cosgrove DJ (1993) How do plant cell walls extend? Plant Physiol 102:1-6

Cosgrove DJ (2005a) Growth of the plant cell wall. Nature 6:850

Cosgrove DJ (2005b) Growth of the plant cell wall. Nat Rev Mol Cell Biol 6:850-861

Cosgrove DJ (2015) Plant expansins: diversity and interactions with plant cell walls. Curr Opin Plant Biol 25:162-172

Covington AK, Bates RG, Durst RA (1985) Definitions of pH scales, standard reference values, measurement of $\mathrm{pH}$, and related terminology. Pure Appl Chem 57:531-542

Damineli DSC, Portes MT, Feijó JA (2015) One thousand and one oscillators at the pollen tube tip: the Quest for a central pacemaker. In: Manusco S, Shabala S (eds) Rhytms in plants. Springer, Geneva

Damineli DSC, Portes MT, Feijó JA (2017) Oscillatory signatures underlie growth regimes in Arabidopsis pollen tubes: computational methods to estimate tip location, periodicity, and synchronization in growing cells. J Exp Bot 68:3267-3281

De Gennes PG (1991) The Nobel Prize in physics. http://www.nobel prize.org/nobel_prizes/physics/laureates/1991/press.html

Dockter C, Gruszka D, Braumann I, Druka A, Druka I, Franckowiak J, Gough SP, Janeczko A, Kurowska M, Lundqvist J, Lundqvist U, Marzec M, Matyszczak I, Müller AH, Oklestkova J, Schulz B, Zakhrabekova S, Hansson M (2014) Induced variations in brassinosteroid genes define barley height and sturdiness, and expand the green revolution genetic toolkit. Plant Physiol 166:1912-1927

Dyson RJ, Band LR, Jensen OE (2012) A model of crosslink kinetics in the expanding plant cell wall: yield stress and enzyme action. J Theor Biol 307:125-136

Fabian C, Reimann C, Fabian K, Birke M, Baritz R, Haslinger E (2014) GEMAS: spatial distribution of the $\mathrm{pH}$ of European agricultural and grazing land soil. Appl Geochem 48:207-216

Feijó JA (1999) The pollen tube oscillator: towards the molecular mechanism of tip growth? In: Cresti M, Cai G, Moscatelli A (eds) Fertilization in higher plants: molecular and cytological aspects. Springer, Berlin, pp 317-336

Feijo JA, Sainhas J, Holdaway-Clarke TL, Cordeiro MS, Kunkel JG et al (2001) Cellular oscillations and the regulation of growth: the pollen tube paradigm. BioEssays 23:86-94

Feynman RP, Hibbs AR (1965) Quantum mechanics and path integrals. McGraw-Hill Companies Inc., New York

Fishel EA, Dixit R (2013) Role of nucleation in cortical microtubule array organization: variations on a theme. Plant J 75:270-277

Fisher ME (1966) Quantum corrections to critical-point behavior. Phys Rev Lett 16:11-14

Fogg GE (1975) The growth of plants. The Chaucer Press, Hanover

Fry SC, Smith SC, Renwick KF, Martin DJ, Hodge SK, Matthews KJ (1992) Xyloglucan endotransglucoselase, a new wall-loosening enzyme activity from plants. Biochem J 282:821-828

Geitmann A (2010) Mechanical modelling and structural analysis of the primary plant cell wall. Curr Opin Plant Biol 13:693-699 
Geitmann A, Cresti M (1998) $\mathrm{Ca}^{2+}$ channels control the rapid expansions in pulsating growth of Petunia hybrida pollen tubes. J Plant Physiol 152:439-447

Geitmann A, Parre E (2004) The local cytomechanical properties of growing pollen tubes correspond to the axial distribution of structural cellular elements. Sex Plant Reprod 17:9-16

Ginzburg VL (2004) On superconductivity and superfluidity (what I have and have not managed to do), as well as on the 'physical minimum' at the beginning of the 21 st century. ChemPhysChem 5:930-945

Grams TE, Lautner S, Felle HH, Matyssek R, Fromm J (2009) Heatinduced electrical signals affect cytoplasmic and apoplastic $\mathrm{pH}$ as well as photosynthesis during propagation through the maize leaf. Plant Cell Environ 32:319-326

Griffiths RB (1970) Thermodynamics near the two-fluid critical mixing point in $\mathrm{He}^{3}-\mathrm{He}^{4}$. Phys Rev Lett 24:1479-1482

Haduch-Sendecka A, Pietruszka M, Zajdel P (2014) Power spectrum, growth velocities and cross-correlations of longitudinal and transverse oscillations of individual Nicotiana tabacum pollen tube. Planta 240:263-276

Hager A (2003) Role of the plasma membrane $\mathrm{H}^{+}$-ATPase in auxininduced elongation growth: historical and new aspects. J Plant Res 116:483-505

Hager A, Mentzel H, Krauss A (1971) Versuche und hypothese zur primaervirkung des auxins beim steckungswastum. Planta 100:47-75

Hepler PK, Winship LJ (2010) Calcium at the cell wall-cytoplast interface. J Integr Plant Biol 52:147-160

Hepler PK, Vidali L, Cheung AY (2001) Polarized cell growth in higher plants. Annu Rev Cell Dev Biol 17:159-187

Hesse J, Gross T (2014) Self-organized criticality as a fundamental property of neural systems. Front Syst Neurosci 8:1-14

Higashiyama T, Takeuchi H (2015) The mechanism and key molecules involved in pollen tube guidance. Annu Rev Plant Biol 66:393-413

Hocken R, Moldover MR (1976) Ising critical exponents in real fluids: an experiment. Phys Rev Lett 37:29

Holdaway-Clarke TL, Hepler PK (2003) Control of pollen tube growth: role of ion gradients and fluxes. New Phytol 159:539-563

Holdaway-Clarke TL, Feijó JA, Hackett GR, Kunkel JG, Hepler PK (1997) Pollen tube growth and the intracellular cytosolic calcium gradient oscillate in phase while extracellular calcium influx is delayed. Plant Cell 9:1999-2010

Hu Z, Yan H, Yang J, Yamaguchi S, Maekawa M, Takamure I, Tsutsumi N, Kyozuka J, Nakazono M (2010) Strigolactones negatively regulate mesocotyl elongation in rice during germination and growth in darkness. Plant Cell Physiol 51:1136-1142

Hubbard J (1963) Electron correlations in narrow energy bands. Proc R Soc 276:238-257

Jung JH, Domijan M, Klose C, Biswas S, Ezer D, Gao M, Khattak AK, Box MS, Charoensawan V, Cortijo S, Kumar M, Grant A, Locke JC, Schäfer E, Jaeger KE, Wigge PA (2016) Phytochromes function as thermosensors in Arabidopsis. Science 354(6314):886-889

Koltai H, Dor E, Hershenhorn J, Joel DM, Weininger S, Lekalla S, Shealtiel H, Bhattacharya C, Eliahu E, Resnick N, Barg R, Kapulnik Y (2010) Strigolactones' effect on root growth and root-hair elongation may be mediated by auxin-efflux carriers. J Plant Growth Regul 29:129-136

Kutschera U (1994) The current status of the acid-growth hypothesis. New Phytol 126:549-569

Kutschera U (2000) Cell expansion in plant development. Braz J Plant Physiol 12:65-95

Landau LD, Lifshitz EM (1980) Statistical physics. ButterworthHeinemann, Oxford
Lewicka S, Pietruszka M (2008) Central limit theorem and the shortterm temperature response of coleoptile and hypocotyl elongation growth. Acta Soc Bot Pol 4:289-292

Li Y, Darley CP, Ongaro V, Fleming A, Schipper O, Baldauf SL, McQueen-Mason SJ (2002) Plant expansins are a complex multigene family with an ancient evolutionary origin. Plant Physiol 128:854-864

Lintilhac PM (2014) The problem of morphogenesis: unscripted biophysical control systems in plants. Protoplasma 251:25-36

Locascio A, Blázquez MA, Alabadí D (2013) Dynamic regulation of cortical microtubule organization through prefoldin-DELLA interaction. Curr Biol 23:804-809

Lockhart A (1965) Analysis of irreversible plant cell elongation. J Theor Biol 8:264-275

Lüthen H (2015) What we can learn from old auxinology. J Plant Growth Regul 34:702-707

Lüthen H, Bigdon M, Böttger M (1990) Re-examination of the acid growth theory of auxin action. Plant Physiol 93:931-939

Majda M, Robert S (2018) The role of auxin in cell wall expansion. Int J Mol Sci 19:951. https://doi.org/10.3390/ijms19040951

Mangano S, Pacheco JS, Marino-Buslje C, Estevez JM (2018) How does $\mathrm{pH}$ fit in with oscillating polar growth? Trends Plant Sci 1654:1-11

Marzec M, Kurczynska EU (2014) Importance of symplasmic communication in cell differentiation. Plant Signal Behav 9:e27931

Marzec M, Muszyńska A (2015) In silico analysis of the genes encoding proteins that are involved in the biosynthesis of the RMS/MAX/D pathway revealed new roles of strigolactones in plants. Int J Mol Sci 16:6757-6782

Marzec M, Melzer M, Szarejko I (2013a) Asymmetric growth of root epidermal cells is related to the differentiation of root hair cells in Hordeum vulgare (L.). J Exp Bot 64:5145-5155

Marzec M, Muszyńska A, Gruszka D (2013b) The role of strigolactones in nutrient-stress responses in plants. Int J Mol Sci 14:9286-9304

Marzec M, Melzer M, Szarejko I (2015a) Root hair development in the grasses: what we already know and what we still need to know? Plant Physiol 168:407-414

Marzec M, Szarejko I, Melzer M (2015b) Arabinogalactan proteins are involved in root hair development in barley. J Exp Bot 66:1245-1257

Matlak M, Pietruszka M (2000) Critical behaviour of the chemical potential at phase transitions. Phys B 291:12-18

Matlak M, Pietruszka M (2001) Comparative study of the specific heat and chemical potential at phase transitions. Solid State Commun 117:413-417

Matlak M, Pietruszka M, Gosławska E, Grabiec B, Eid Kh (2000) On the new universal possibility to detect phase transitions in correlated electron systems. Phase Trans 71:73-99

Matlak M, Pietruszka M, Rówiński E (2001) Experimental method to detect phase transitions via the chemical potential. Phys Rev B 63:052101-1-052101-3

Matlak M, Molak A, Pietruszka M (2004) Chemical potential induced phase transitions. Phys Status Solidi 241:R23-R26

McQueen-Mason S, Cosgrove DJ (1994) Disruption of hydrogen bonding between wall polymers by proteins that induce plant wall extension. Proc Natl Acad Sci USA 91:6574-6578

Messerli MA, Robinson KR (1997) Tip localized $\mathrm{Ca}^{2+}$ pulses are coincident with peak pulsatile growth rates in pollen tubes of Lilium longiflorum. J Cell Sci 110:1269-1278

Messerli MA, Robinson KR (1998) Cytoplasmatic acidification and current influx follow growth pulses of Lilium longiflorum pollen tubes. Plant J 16:87-91

Messerli MA, Danuser G, Robinson KR (1999) Pulsatile influxes of $\mathrm{H}^{+}, \mathrm{K}^{+}$, and $\mathrm{Ca}^{2+}$ lag growth pulses in Lilium longiflorum. $\mathrm{J}$ Cell Sci 112:1497-1509 
Michard E, Simon AA, Tavares B, Wudick MM, Feijó JA (2016) Signalling with ions: the keystone for apical cell growth and morphogenesis in pollen tubes. Plant Physiol. https://doi. org/10.1104/pp.16.01561

Obermayer G (2017) Water transport in pollen. In: Obermayer G, Feijo J (eds) Pollen tip growth: from biophysical aspects to systems biology. Springer Nature, New York, pp 15-34

Okamoto-Nakazato A, Takahashi K, Katoh-Semba R, Katou K (2001) Distribution of yieldin, a regulatory protein of the cell wall field threshold in etiolated cowpea seedlings. Plant Cell Physiology 42:952-958

Olszewska M, Konefał A, Pietruszka M (2017) Proton kinetics through the cuticle layer in maize. Acta Physiol Plant 39:257

Olszewska M, Haduch-Sendecka A, Pietruszka M (2018) Determination of selected dynamic quantities of growing intact seeds of maize. Gen Physiol Biophys 37:375-389

Ortega JKE (1985) Augmented growth equation for cell wall expansion. Plant Physiol 79:318-320

Ortega JKE (2018) Dimensionless numbers for Plant Biology. Trends Plant Sci. https://doi.org/10.1016/j.tplants.2017.09.020

Ortega JKE, Truong JT, Munoz CM, Ramirez DG (2015) Cell wall loosening in the Fungus, Phycomyces blakesleeanus. Plants (Basel Switzerland) 4:63-84

Paredez AR, Somerville CR, Ehrhardt DW (2006) Visualization of cellulose synthase demonstrates functional association with microtubules. Science 312:1491-1495

Parton RM, Fischer-Parton S, Trewavas AJ, Watahiki MK (2003) Pollen tubes exhibit regular periodic membrane trafficking events in the absence of apical extension. J Cell Sci 116:2707-2719

Pierson ES, Miller DD, Callaham DA, Shipley AM, Rivers BA, Cresti M, Hepler PK (1994) Pollen tube growth is coupled to the extracellular calcium ion flux and the intracellular calcium gradient: effect of BAPTA-type buffers and hypotonic media. Plant Cell 6:1815-1828

Pietruszka M (2011) Solutions for a local equation of anisotropic plant cell growth: an analytical study of expansin activity. J R Soc Interface 8(60):975-987

Pietruszka M (2012) A biosynthesis/inactivation model for enzymatic WLFs or non-enzymatically mediated cell evolution. J Theor Biol 315:19-127

Pietruszka M (2013) Pressure-induced cell wall instability and growth oscillations in pollen tubes. PLoS ONE 8:e75803

Pietruszka, M, Olszewska M (2019) Cell life - at the 1/f edge of chaos? Eur Biophys J. In review

Pietruszka M, Haduch-Sendecka A (2015a) Pressure-induced wall thickness variations in multi-layered wall of a pollen tube and Fourier decomposition of growth oscillations. Gen Physiol Biophys 34:145-156

Pietruszka M, Haduch-Sendecka A (2015b) Ion frequency landscape in growing plants. PLoS ONE 10:e0138839

Pietruszka M, Haduch-Sendecka A (2016) Effective diffusion rates and cross-correlation analysis of "acid growth" data. Acta Physiol Plant 38:53

Pietruszka M, Lewicka S (2007) Anisotropic plant growth due to phototropism. J Math Biol 54:45-55

Pietruszka M, Lewicka S, Pazurkiewicz-Kocot K (2007) Temperature and the growth of plant cells. J Plant Growth Regul 26:15-25

Pietruszka M, Olszewska M, Machura L, Rówiński E (2018) Single measurement detection of individual cell ionic oscillations using an n-type semiconductor-electrolyte interface. Sci Rep 8:7875

Plyushch TA, Willemse MTM, Franssen-Verheijen MAW, Reinders MC (1995) Structural aspects of in vitro pollen tube growth and micropylar penetration in Gasteria verrucosa (Mill.) H. Duval and Lilium longiflorum thumb. Protoplasma 187:13-21
Polyanin AD, Chernoutsan AI (2011) A concise handbook of mathematics, physics and engineering. CRC Press, Boca Raton

Portes MT, Damineli DSC, Moreno N, Colaco R, Feijo JA (2015) The pollen tube oscillator: integrating biophysics and biochemistry into cellular growth and morphogenesis. In: Manusco S, Shabala $\mathrm{S}$ (eds) Rhytms in plants. Springer, New York

Proseus TE, Boyer JS (2006) Identifying cytoplasmatic input to the cell wall of growing Chara coralline as a model system. J Exp Bot 51:3231-3242

Proseus TE, Boyer JS (2007) Tension required for pectate chemistry to control growth in Chara corallina. J Exp Bot 57:3989-4002

Proseus TE, Zou G-L, Boyer JS (2000) Turgor, temperature and the growth of plant cells: using Chara coralline as a model system. J Exp Bot 51:1481-1494

Racz Z (2002) Nonequilibrium phase transitions. https://arxiv.org/abs/ cond-mat/0210435

Ray PM, Green PB, Cleland RE (1972) Role of turgor in plant cell growth. Nature 239:163-164

Rayle DL, Cleland RE (1970) Enhancement of wall loosening and elongation by acid solutions. Plant Physiol 46:250-253

Rayle DL, Cleland RE (1992) The acid growth theory of auxin-induced cell elongation is alive and well. Plant Physiol 99:1271-1274

Rojas ER, Hotton S, Dumais J (2011) Chemically mediated mechanical expansion of the pollen tube cell wall. Biophys J 101:1844-1853

Rounds CM, Hepler PK, Fuller SJ, Winship LJ (2010) Oscillatory growth in lily pollen tubes does not require aerobic energy metabolism. Plant Physiol 152:736-746

Schopfer P (2006) Biomechanics of plant growth. Am J Bot 93:1415-1425

Schopfer P (2008) Is the loss of stability theory a realistic concept for stress relaxation-mediated cell wall expansion during plant growth? Plant Physiol 147:935-938

Schrödinger E (1944) What is life?. Cambridge University Press, Cambridge

Sherstneva ON, Vodeneev VA, Katicheva LA, Vodeneev VA, Sukhov VS (2015) Participation of intracellular and extracellular $\mathrm{pH}$ changes in photosynthetic response development induced by variation potential in pumpkin seedlings. Biochemistry (Moscow) 80:776-784

Shinohara N, Taylor C, Leyser O (2013) Strigolactone can promote or inhibit shoot branching by triggering rapid depletion of the auxin efflux protein PIN1 from the plasma membrane. PLoS Biol 11:e1001474

Smithers ET, Luo J, Dyson RJ (2019) Mathematical principles and models of plant growth mechanics: from cell wall dynamics to tissue morphogenesis. J Exp Bot 70:3587-3600

Sridhar SL, Ortega JKE, Vernerey FJ (2018) A statistical model of expansive growth in plant and fungal cells: the case of phycomyces. Biophys J 115:2428-2442

Stanley HE (1971) Introduction to phase transitions and critical phenomena. Oxford University Press, Oxford

Steinacher A, Leyser O, Clayton R (2012) A computational model of auxin and $\mathrm{pH}$ dynamics in a single plant cell. J Theor Biol 296:84-94

Sukhov VS, Nerush V, Orlova L, Vodeneev V (2011) Simulation of action potential propagation in plants. J Theor Biol 291:47-55

Sukhov V, Sherstneva O, Surova L, Katicheva L, Vodeneev V (2014) Proton cellular influx as a probable mechanism of variation potential influence on photosynthesis in pea. Plant Cell Environ 3:1541-2532

Sukhov V, Surova L, Morozova E, Sherstneva O, Vodeneev V (2016) Changes in $\mathrm{H}^{+}$-ATP synthase activity, proton electrochemical gradient, and $\mathrm{pH}$ in pea chloroplast can be connected with variation potential. Front Plant Sci 7:1092

Taiz L, Zeiger E (2006) Plant physiology, 4th edn. Sinauer Associates Inc. Publishers, Massachusets 
Tang C, Bak P (1988) Critical exponents and scaling relations for self-organized critical phenomena. Phys Rev Lett 60:2347-2350

van der Marel D (2004) Electrons and bursting waterworks. Physica Status Solidi (b) 241:1391-1392

Van Hemelryck M, Bernal R, Rojas E, Dumais J, Kroeger JH (2017) A fresh look at growth oscillations in pollen tubes: kinematic and mechanistic descriptions. In: Obermayer G, Feijo J (eds) Pollen tip growth. Springer, New York

Van Hemelryck M, Bernal R, Ispolatov Y, Dumais J (2018) Lily pollen tubes pulse according to a simple spatial oscillator. Sci Rep 8:12135. https://doi.org/10.1038/s41598-018-30635-y

Vazquez LA, Sanchez R, Hernandez-Barrera A, Zepeda-Jazo I, Sánchez F, Quinto C, Torres LC (2014) Actin polymerization drives polar growth in Arabidopsis root hair cells. Plant Signal Behav 9:e29401

Vitt P, Havens K, Kramer AT, Sollenberger D, Yates E (2010) Assisted migration of plants: changes in latitudes, changes in attitudes. Biol Cons 143:18-27

Wei C, Lintilhac PM (2003) Loss of stability - a new model for stress relaxation in plant cell walls. J Theor Biol 224:305-312

Wei C, Lintilhac PM (2007) Loss of stability: a new look at the physics of cell wall behaviour during plant cell growth. Plant Physiol 145:763-772

Wei C, Lintilhac PM (2008) Response to Schopfer letter. Plant Physiol 147:936-937

Wei C, Lintilhac LS, Lintilhac PM (2006) Loss of stability, pH and the anisotropic extensibility of Chara cell walls. Planta 223:1058-1067

Went FW (1953) The effect of temperature on plant growth. Annu Rev Plant Physiol 4:347-362

Willats WG, Knox JP (1996) A role for arabinogalactan-proteins in plant cell expansion: evidence from studies on the interaction of $\beta$-glucosyl Yariv reagent with seedlings of Arabidopsis thaliana. Plant J 9:919-925

Winship L, Obermeyer G, Geitmann A, Hepler PK (2010) Under pressure, cell walls set the pace. Trends Plant Sci 15:363-369

Winship L, Obermeyer G, Geitmann A, Hepler PK (2011) Pollen tubes and the physical world. Trends Plant Sci 16:353-355

Wojtaszek P, Baluška F, Kasprowicz A, Luczak M, Volkmann D (2007) Mechanosensory transmission of cell wall disturbances to the actin cytoskeleton in maize root apex cells. Protoplasma 230:217-230

Yan W, Hunt LA (1999) An equation modelling the temperature response of plants using only the cardinal temperatures. Ann Bot 84:607-614

Zajdel P, Pietruszka M, Haduch-Sendecka A (2016) Application of the effective formula of growth functional to quantitative description of growth of plant cells. Acta Physiol Plant 38:216

Zonia L (2010) Spatial and temporal integration of signalling networks regulating pollen tube growth. J Exp Bot 61:1939-1957

Zonia L, Munnik T (2007) Life under pressure: hydrostatic pressure in cell growth and function. Trends Plant Sci 12:90-97

Zonia L, Munnik (2008) Vesicle trafficking dynamics and visualization of zones of exocytosis and endocytosis in tobacco pollen tubes. J Exp Bot 59:861-873

Zonia L, Müller M, Munnik T (2006) Hydrodynamics and cell volume oscillations in the pollen tube apical region are integral components of biomechanics of the Nicotiana tabaccum pollen tube growth. Cell Biochem Biophys 46:209-232

Publisher's Note Springer Nature remains neutral with regard to jurisdictional claims in published maps and institutional affiliations. 